\title{
Well-defined cobalt sulfide nanoparticles locked in 3D hollow nitrogen-doped carbon shells for superior lithium and sodium storage
}

Shangguan, Huihui; Huang, Wei; Engelbrekt, Christian; Zheng, Xiaowen; Shen, Fei; Xiao, Xinxin; Ci, Lijie; Si, Pengchao; Zhang, Jingdong

\author{
Published in: \\ Energy Storage Materials
}

Link to article, DOI:

10.1016/j.ensm.2019.01.012

Publication date:

2019

Document Version

Peer reviewed version

Link back to DTU Orbit

Citation (APA):

Shangguan, H., Huang, W., Engelbrekt, C., Zheng, X., Shen, F., Xiao, X., Ci, L., Si, P., \& Zhang, J. (2019). Welldefined cobalt sulfide nanoparticles locked in 3D hollow nitrogen-doped carbon shells for superior lithium and sodium storage. Energy Storage Materials, 18, 114-124. https://doi.org/10.1016/j.ensm.2019.01.012

\section{General rights}

Copyright and moral rights for the publications made accessible in the public portal are retained by the authors and/or other copyright owners and it is a condition of accessing publications that users recognise and abide by the legal requirements associated with these rights.

- Users may download and print one copy of any publication from the public portal for the purpose of private study or research.

- You may not further distribute the material or use it for any profit-making activity or commercial gain

- You may freely distribute the URL identifying the publication in the public portal 


\section{Well-Defined Cobalt Sulfide Nanoparticles Locked in 3D Hollow Nitrogen-Doped Carbon Shells for Superior Lithium and Sodium Storage}

Huihui Shangguan, ${ }^{a, 1}$ Wei Huang, ${ }^{b, 1}$ Christian Engelbrekt, ${ }^{b, c}$ Xiaowen Zheng, ${ }^{a}$ Fei Shen, ${ }^{b}$

5 Xinxin Xiao, ${ }^{\mathrm{b}, \mathrm{d}}$ Lijie Ci, ${ }^{\mathrm{a}}$ Pengchao $\mathrm{Si}^{\mathrm{a},}{ }^{*}$ and Jingdong Zhang ${ }^{\mathrm{b}, *}$

${ }^{a}$ SDU \& Rice Joint Center for Carbon Nanomaterials, Key Laboratory for Liquid-Solid Structural Evolution and Processing of Materials, Ministry of Education, School of Materials Science and Engineering, Shandong University, Jinan 250061, P. R. China.

$10{ }^{b}$ Department of Chemistry, Technical University of Denmark, DK-2800 Kongens Lyngby, Denmark.

${ }^{c}$ Department of Chemistry, University of California Irvine, Irvine, California, 92697, United States.

${ }^{d}$ Department of Chemical Sciences and Bernal Institute, University of Limerick, Limerick, Ireland.

ABSTRACT: Hollow nanostructured materials present a class of promising electrode materials for energy storage and conversion. Herein, 3D hollow nitrogen-doped carbon shells decorated with well-defined cobalt sulfide nanoparticles ( $\mathrm{Co}_{9} \mathrm{~S}_{8} / \mathrm{HNCS}$ ) have been constructed for superior lithium and sodium storage. Two steps are involved in the designed preparation procedure. First, hollow intermediates with preserved cobalt components are controllably fabricated by simultaneously dissociating cobalt containing zeolitic-imidazolateframeworks-67 (ZIF-67), and polymerizing dopamine in a Tris- $\mathrm{HCl}$ solution $(\mathrm{pH}=8.5)$. The poly-dopamine (PDA) wrapped intermediates inherits the polyhedral structure of the ZIF-67 crystals. In the second step, the final $\mathrm{Co}_{9} \mathrm{~S}_{8} / \mathrm{HNCS}$ composite is obtained via a combined carbonization and sulfurization treatment of the intermediates, allowing the formation of hollow polyhedrons of nitrogen-doped carbon shells $(900 \pm 100 \mathrm{~nm})$ derived from PDA and the encapsulation of highly uniform cobalt sulfide nanoparticles (11 $\pm 2 \mathrm{~nm}$ ). This 
configuration is believed to not only shorten the lithium or sodium ion diffusion distance and accommodate volume change during lithium or sodium ion insertion/extraction, but also to enhance the overall electrical conductivity and the number of active sites. As a result, the $\mathrm{Co}_{9} \mathrm{~S}_{8} / \mathrm{HNCS}$ composite exhibits an impressive reversible capacity of $755 \mathrm{~mA} \mathrm{~h} \mathrm{~g}^{-1}$ at $500 \mathrm{~mA}$

$5 \mathrm{~g}^{-1}$ after 200 cycles for lithium ion storage, and capacities of $327 \mathrm{~mA} \mathrm{~h} \mathrm{~g}^{-1}$ at $500 \mathrm{~mA} \mathrm{~g}^{-1}$ after 200 cycles and $224 \mathrm{~mA} \mathrm{~h} \mathrm{~g}^{-1}$ at $1000 \mathrm{~mA} \mathrm{~g}^{-1}$ after 300 cycles for sodium ion storage. Essential factors especially the structural stability during cycling have been identified, and the discharge/charge mechanism is discussed.

10 Keywords: Cobalt sulfide, hollow structure, metal organic framework, lithium ion storage, sodium ion storage. 


\section{Introduction}

To meet the increasing demands for energy storage in renewable energy economy, the development of secondary battery technologies such as lithium and sodium ion batteries (LIBs and SIBS) has invariably gained great attention. Two main reactive modes (i.e. intercalation and conversion) are responsible for LIBs and SIBs [1]. In comparison to the intercalation reaction occurring in carbonaceous materials with no more than one electron transferred, conversion reactions can transfer numerous electrons (2-6 electrons), and thus possess higher theoretical capacity [1-3]. However, cracks and pulverization found in conversion-type materials, as results of significant volumetric change during cycling, alongside with sluggish ion diffusion within the electrode materials, lead to large capacity loss and weak rate capability. Tremendous efforts have been dedicated to developing robust conversion-type materials to replace the traditional intercalation materials [4-10]. Cobalt sulfides $\left(\mathrm{CO}_{x} \mathrm{~S}_{\mathrm{y}}\right)$, a subgroup of transition metal sulfides (TMSs) with excellent electrochemical activity and high theoretical capacity ( $>400 \mathrm{~mA} \mathrm{~h} \mathrm{~g}{ }^{-1}$ ), have been investigated as promising conversion-type electrode materials [11-16].

To shorten the diffusion path for high rate performance, decreasing the particle-sizes of $\mathrm{Co}_{x} \mathrm{~S}_{y}$ is a well-recognized approach [17-19]. In addition, incorporating $\mathrm{Co}_{x} \mathrm{~S}_{y}$ into a carbonaceous framework can effectively promote electrical conductivity and accommodate its volumetric change for enhanced cycling stability [17-21]. For example, Wu and coworkers have reported a graphene paper $/ \mathrm{Co}_{9} \mathrm{~S}_{8}$ nanocomposite for high-performance LIBs, delivering a capacity of $538.69 \mathrm{~mA} \mathrm{~h} \mathrm{~g} \mathrm{~g}^{-1}$ at $1090 \mathrm{~mA} \mathrm{~g}$. The good electrochemical performance was benefited from the unique structure with $\mathrm{Co}_{9} \mathrm{~S}_{8}$ nanoparticles (ca. $25 \mathrm{~nm}$ ) uniformly dispersed on the surface of highly conductive graphene sheets [20]. Wang et al. have prepared $\mathrm{CoS}_{2} /$ multi-walled carbon nanotubes (MWCNTs) nanocomposites for SIBS with a capacity of $242.3 \mathrm{~mA} \mathrm{~h} \mathrm{~g}^{-1}$ at $800 \mathrm{~mA} \mathrm{~g}^{-1}$ [21]. Besides, introducing nitrogen atoms to porous carbon materials can alter the chemical and electronic properties of carbonaceous components for enhanced electrochemical performance $[22,23]$. It is not surprisingly to see increasing interest in developing $\mathrm{Co}_{x} \mathrm{~S}_{y} / \mathrm{N}$ doped carbon hybrids [24, 25]. However, those hybrids are generally fabricated by post-modification processes, lacking integral structural design and excellent rate performance. Furthermore, hollow micro/nanostructured carbonaceous materials with large specific surface area can enable more active sites 
displayed and ensure shorter ion/electron diffusion pathways [26-29]. For example, Qian and co-workers have encapsulated $\mathrm{CO}_{1-\mathrm{x}} \mathrm{S}$ nanoparticles in nitrogen-doped porous carbon hollow nanospheres for superior lithium and sodium storage. The materials demonstrated a discharge capacity of $320 \mathrm{~mA} \mathrm{~h} \mathrm{~g}^{-1}$ for sodium storage at $1000 \mathrm{~mA} \mathrm{~g}^{-1}$ after 130 cycles and $559 \mathrm{~mA} \mathrm{~h} \mathrm{~g}^{-1}$ for lithium storage at $500 \mathrm{~mA} \mathrm{~g}^{-1}$ after 100 cycles [29]. Inspired by the previous reports, highly homogeneous cobalt sulfide nanoparticles embedded in a nitrogen-doped carbon matrix with integral hollow structure are of significant interest for high-performance LIBs and SIBs.

Metal-organic frameworks (MOFs) formed by assembly of metal units and organic linkers with unique structure and component functionalities, offer great opportunities as templates or precursors for hollow structured materials [30-36]. For example, Chen and co-workers have reported MOFs derived CoP nanoparticle-embedded $\mathrm{N}$-doped carbon nanotube hollow polyhedron for overall water splitting, utilizing the as-prepared ZIF-8@ZIF-67 as the precursor for pyrolysis and following phosphorization [35]. Wang et. al have fabricated the hollow metal (Co or $\mathrm{Zn}$ )/N-doped carbon particles with excellent oxygen reduction electrocatalytic activity. The precursors were hollow-structured PDA with coordinated assembly of metal ions (Co or Zn) originated from the ZIF-67 or ZIF-8 [36]. PDA wrapping of the well-structured MOF crystals, which were simultaneously dissolved in a slightly alkaline solution, results in PDA intermediates preserving the leaked metal ions and imprinted hollow structure of MOF crystals (Scheme 1). The intermediates can be subsequently treated for various desired functional materials and the versatile approach allows the preparation of a wide range of metal-based materials. Pioneering works on MOFs derived $\mathrm{Co}_{9} \mathrm{~S}_{8}$ nanoparticles have been reported $[37,38]$. However, those nanocomposites did not well inherit the precursor polyhedral configuration, showing limited electrochemical performance. For example, Zhu et. al have synthesized ZIF-67 derived $\mathrm{Co}_{9} \mathrm{~S}_{8}$ nanoparticles encapsulated in nitrogen-doped carbon networks with a constringent polyhedral morphology, without showing a high-current-density cycling ability [37]. Yu and coworkers have fabricated ZIF-67 derived $\mathrm{Co}_{9} \mathrm{~S}_{8} @ \mathrm{C}$ nanocages with absolute hollow interiors, while only delivers $54 \mathrm{~mA} \mathrm{~h} \mathrm{~g}^{-1}$ for lithium storage after 30 cycles at $544 \mathrm{~mA} \mathrm{~g}^{-1}$ [38]. To the best of our knowledge, there is no report on utilizing PDA derived nitrogen doped carbon layers to embed ZIF-67 derived $\mathrm{Co}_{9} \mathrm{~S}_{8}$ nanoparticles for enhanced lithium or sodium storage 
performance. Moreover, significant challenge lies in the controllable synthesis of MOFs derived $\mathrm{Co}_{9} \mathrm{~S}_{8}$ nanocomposites showing uniform decoration of $\mathrm{Co}_{9} \mathrm{~S}_{8}$ nanoparticles immobilized in hollow nitrogen-doped carbon shells.

Herein, we demonstrate a synthetic strategy of cobalt sulfide nanoparticles

5 homogeneously locked in 3D hollow nitrogen-doped carbon shells ( $\mathrm{Co}_{9} \mathrm{~S}_{8} / \mathrm{HNCS}$ ) for highperformance lithium and sodium storage. PDA intermediates retaining of the Co cations and polyhedral structure of ZIF-67 crystals are prepared (Scheme 1). Key parameters including the concentration of dopamine hydrochloride (DAH) are examined to evaluate their effects on the resulted intermediate morphology. After carbonization and the subsequent sulfurization (Scheme 1), $\mathrm{Co}_{9} \mathrm{~S}_{8} / \mathrm{HNCS}$ composite is obtained with highly monodisperse $\mathrm{Co}_{9} \mathrm{~S}_{8}$ nanoparticles (11 $\pm 2 \mathrm{~nm}$ ) embedded in 3D hollow nitrogen-doped carbon shells. $\mathrm{Co}_{9} \mathrm{~S}_{8} / \mathrm{HNCS}$ is tested for batteries, exhibiting an impressive reversible capacity of $755 \mathrm{~mA} \mathrm{~h}$ $\mathrm{g}^{-1}$ at $500 \mathrm{~mA} \mathrm{~g}^{-1}$ after 200 cycles for lithium storage, and superior capacities of $327 \mathrm{~mA} \mathrm{~h} \mathrm{~g}^{-1}$ at $500 \mathrm{~mA} \mathrm{~g}^{-1}$ after 200 cycles and $224 \mathrm{~mA} \mathrm{~h} \mathrm{~g}^{-1}$ at $1000 \mathrm{~mA} \mathrm{~g}^{-1}$ after 300 cycles for sodium storage. The excellent electrochemical performance is ascribed to the synergistic effects of nanosized cobalt sulfide particles and nitrogen-doped carbon polyhedral shells combined in the unique porous hollow configuration.

\section{Experimental}

\subsection{Chemicals and Reagents}

Cobaltous nitrate hexahydrate $\left(\mathrm{Co}\left(\mathrm{NO}_{3}\right)_{2} \cdot 6 \mathrm{H}_{2} \mathrm{O}, 99 \%\right)$, 2-methy-limidazole $\left(\mathrm{C}_{4} \mathrm{H}_{6} \mathrm{~N}_{2}, 98 \%\right)$, dopamine hydrochloride (DAH, $\mathrm{C}_{8} \mathrm{H}_{11} \mathrm{NO}_{2} \cdot \mathrm{HCl}, 98 \%$ ), tris(hydroxymethyl)aminomethane hydro-chloride (Tris $\mathrm{HCl}, \geq 99 \%)$, thiourea $\left(\mathrm{CH}_{4} \mathrm{~N}_{2} \mathrm{~S}, \geq 99 \%\right)$ were purchased from Aladdin, China. Methanol $\left(\mathrm{CH}_{4} \mathrm{O}, \geq 99.5 \%\right)$ and ethanol $\left(\mathrm{C}_{2} \mathrm{H}_{6} \mathrm{O}, \geq 99.7 \%\right)$ were obtained from Sinopharm Chemical Reagent Co., Ltd. All chemicals were used as received without further purification. Ultrapure water $(>18.25 \mathrm{M} \Omega \mathrm{cm})$ was used to prepare all the aqueous solutions.

\subsection{Synthesis of hollow $\mathrm{CO}_{9} \mathrm{~S}_{8} / \mathrm{HNCS}$ composite}

ZIF-67 crystals were fabricated according to a modified procedure [34]. Briefly, $\mathrm{Co}\left(\mathrm{NO}_{3}\right)_{2} \cdot 6 \mathrm{H}_{2} \mathrm{O}(498 \mathrm{mg}$ ) and 2-methylimidazole $(656 \mathrm{mg})$ were dissolved in $100 \mathrm{~mL}$ 
methanol to form a uniform solution, which was left at room temperature for $24 \mathrm{~h}$ to form ZIF-67 crystals. The obtained ZIF-67 crystals were purified with centrifugation and washing with methanol at least three times.

A poly-dopamine (PDA) layer was subsequently introduced to the surface of the ZIF-67 crystals. 120 mg ZIF-67 crystals were added into DAH solution (with concentrations of 0.5, 1.0 or $\left.2.0 \mathrm{mg} \mathrm{mL}^{-1}\right)$ in $50 \mathrm{~mL}$ Tris- $\mathrm{HCl}(10 \mathrm{mM}, \mathrm{pH}=8.5)$ and sonicated for $10 \mathrm{~min}$. The mixtures were stirred for $24 \mathrm{~h}$ at room temperature. The solid products were washed with ultrapure water and ethanol separately more than three times. After vacuum drying, the PDA@ZIF-67 composite was obtained.

As-prepared PDA@ZIF-67 composite was annealed at $550{ }^{\circ} \mathrm{C}$ for $1 \mathrm{~h}$ under nitrogen gas. Then, the carbonized PDA@ZIF-67 composites were sulfurized at $400{ }^{\circ} \mathrm{C}$ for $6 \mathrm{~h}$ under $\mathrm{Ar} / \mathrm{H}_{2}$ atmosphere (content of $\mathrm{H}_{2}: 5 \%(\mathrm{v} / \mathrm{v})$ ) using thiourea as the sulfur source. Two individual quartz boats containing thiourea and PDA@ZIF-67 (mass ratio 3:1), respectively, were aligned parallel to the direction of gas flow. The final dark powders ( $\mathrm{Co}_{9} \mathrm{~S}_{8} / \mathrm{HNCS}$ ) were collected. As a reference material, cobalt sulfide nanoparticles coated with nitrogen-doped carbon $\left(\mathrm{Co}_{9} \mathrm{~S}_{8} / \mathrm{NC}\right)$ composite was synthesized according to the same protocol without PDA modification layers.

\subsection{Materials characterization}

The crystalline features of the obtained composites were analyzed by X-ray diffraction (XRD, Miniflex 600). Raman spectra were recorded by a Raman spectrometer (Renishaw InVia, $633 \mathrm{~nm}$ Laser). X-ray photoelectron spectroscopic (XPS) analysis was performed on samples loaded on a silicon substrate with a Thermo-Scientific system (Al-K $\alpha$ radiation, $1484.6 \mathrm{eV})$. Microstructure and composition analysis were conducted with scanning electron microscopy (SEM, HITACHI SU-70, 15 kV; Quanta FEG 200 ESEM, 15 kV), atomicforce microscopy (AFM, Agilent Technology 5500, tapping mode, a mica sheet as the substrate), and transmission electron microscopy (TEM, JEOL 2800, 200 kV; Tecnai G2 T20, $200 \mathrm{kV}$ ). Surface functional groups were determined by Fourier transform infrared spectroscopy (FTIR, Vector 22 spectrometer, Bruker). The specific surface area was estimated by a Surface Area \& Pore Size Analyzer (ASAP 2020, Micromeritics). Thermal 
gravimetric analysis (TGA, Mettler-Toledo TGA/SDTA851e Thermo Analyzer) was performed in air from room temperature to $900{ }^{\circ} \mathrm{C}$ with a heating rate of $5{ }^{\circ} \mathrm{C} \mathrm{min}-1$.

\subsection{Electrochemical measurements}

The working electrodes of half coin cells were prepared by casting the mixture of active materials (70 wt\%), super P (20 wt\%) and polyvinylidene fluoride (PVDF) (10 wt\%) dissolved in N-methyl-2-pyrrolidone (NMP) onto a copper foil. For lithium and sodium ion storage, lithium and sodium foil were used as the counter electrode, respectively. 1.0 M LiPF6 dissolved in a solution composed of dimethyl carbonate, ethylene carbonate, diethyl carbonate (1:1:1 by volume) was used as the electrolyte for lithium ion storage. 1.0 M $\mathrm{NaClO}_{4}$ dissolved in a medium consisting of ethylene carbonate, propylene carbonate (1: 1 wt\%) and $5 \mathrm{wt} \%$ fluoroethylene carbonate was used as the electrolyte for sodium ion storage. Coin-type (CR 2016) batteries were assembled in a glove box under argon atmosphere at room temperature. Neware-CT-3008 test system (Shenzhen, China) was used for galvanostatic charge/discharge tests in a potential window of $0.01-3.0 \mathrm{~V}$. CHI $660 \mathrm{E}$

electrochemical workstation (Shanghai, China) was utilized to record cyclic voltammograms (CVs) in a voltage range of $0.01-3.0 \mathrm{~V}$ at a scan rate of $0.1 \mathrm{mV} \mathrm{s} \mathrm{s}^{-1}$. Electrochemical impedance spectroscopy (EIS) in the frequency range of 0.01 to $100 \mathrm{kHz}$ was carried out at open circuit potential (OCP) using a Metrohm Autolab.

\section{Results and discussion}

20

Formation of PDA@ZIF-67 intermediates. The synthetic strategy of $\mathrm{Co}_{9} \mathrm{~S}_{8} / \mathrm{HNCS}$ composite was shown in Scheme 1. First, as-prepared solid rhombic dodecahedral ZIF-67 crystals with an average particle size of $1100 \pm 100 \mathrm{~nm}$ (Fig. S1 and Fig. S2) were mixed with different concentrations of dopamine hydrochloride (DAH) in Tris- $\mathrm{HCl}(10 \mathrm{mM}, \mathrm{pH}=8.5)$ solution under magnetic stirring. Two processes were likely to occur simultaneously: (1) the dissolution of ZIF-67 crystals in the weak alkaline environment. The 2-methylimidazole (2MIM) linkers in the ZIF-67 become protonated, leading to the breakdown of metal-ligand bonds and the subsequent dissolution of ZIF-67 crystals [39, 40], and (2) oxidation and selfpolymerization of dopamine forming polydopamine (PDA) layers, onto the polyhedron structure of ZIF-67 while immobilizing liberated Co units [41]. 




Scheme 1. Schematic illustration of the preparation of the $\mathrm{Co}_{9} \mathrm{~S}_{8} / \mathrm{HNCS}$ composite. Not drawn to real scale.

Controlling the concentration of DAH is key for the formation of well-defined PDA@ZIF-67 5 intermediates. When the concentration of DAH is $0.5 \mathrm{mg} \mathrm{mL}^{-1}$, the obtained PDA@ZIF-67 samples show a cracked structure (Fig. S3a and b), which are further confirmed by the TEM characterization (Fig. S3c and d). This is a result of insufficient protection by PDA layers. When treated by $2.0 \mathrm{mg} \mathrm{mL}^{-1} \mathrm{DAH}$, the generated PDA@ZIF-67 (Fig. S4) shows the coexistence of both polyhedron-shaped structures and spherical PDA clusters, due to the formation of extra PDA clusters. $1.0 \mathrm{mg} \mathrm{mL}^{-1} \mathrm{DAH}$ is adopted as the optimal concentration where PDA layers maintain the original polyhedral structure $(1000 \pm 100 \mathrm{~nm})$ without excess PDA for spheres formation (Fig. S5a and b). TEM (Fig. S5c and d) further reveals hollow inner voids of the generated polyhedral structure compared with solid ZIF-67 crystals (Fig. S2). This transformation is also confirmed from changes in crystallography. The X-ray diffraction (XRD) pattern of ZIF-67 crystals shows a characteristic crystalline pattern, which is not found for the amorphous-featured PDA@ZIF-67 composite (Fig. S6a). Moreover, Fourier transform infrared spectroscopy (FTIR) verifies the transformation by the disappearance of the band at $420 \mathrm{~cm}^{-1}$ ascribed to Co- $\mathrm{N}$ stretching vibrations of the ZIF-67 crystals in the PDA@ZIF-67 composite (Fig. S6b) [42]. The broad band at $3391 \mathrm{~cm}^{-1}$ is assigned to the $\mathrm{O}-\mathrm{H} \& \mathrm{~N}-\mathrm{H}$ stretching modes in the PDA@ZIF-67 composite [43].

Structural and morphological characteristics of $\mathrm{Co}_{9} \mathrm{~S}_{8} / \mathrm{HNCS}$. Subsequent carbonization and sulfurization of PDA@ZIF-67 is applied to generate the final product, i.e. $\mathrm{Co}_{9} \mathrm{~S}_{8} / \mathrm{HNCS}$. As a reference, a non-PDA-protected material $\left(\mathrm{Co}_{9} \mathrm{~S}_{8} / \mathrm{NC}\right)$ is prepared without PDA coating in Scheme 1 directly carbonizing/sulfurizing ZIF-67 crystals. The generated $\mathrm{Co}_{9} \mathrm{~S}_{8} / \mathrm{HNCS}$ 
composite is confirmed by XRD (Fig. 1a) where all peaks could be indexed to $\mathrm{Co}_{9} \mathrm{~S}_{8}$ (JCPDS no. 65-1765). A broad low-intensity peak is observed at $20-25^{\circ}$ due to the existence of PDA derived carbon [44]. As a control, the broad peak is not found in that of $\mathrm{Co}_{9} \mathrm{~S}_{8} / \mathrm{NC}$ composite (Fig. S7). The Raman spectra (Fig. 1b) reveal an $I_{D} / I_{G}$ intensity ratio of 0.83 for the $\mathrm{Co}_{9} \mathrm{~S}_{8} / \mathrm{HNCS}$ composite which is smaller than that of $\mathrm{Co}_{9} \mathrm{~S}_{8} / \mathrm{NC}(0.94)$, suggesting an increased $\mathrm{sp}^{2}$ hybridization expected to promote electrical conductivity. The presence of cobalt, sulfur, nitrogen and carbon in $\mathrm{Co}_{9} \mathrm{~S}_{8} / \mathrm{HNCS}$ is identified by X-ray photoelectron spectroscopy (XPS, Fig. S8). The high-resolution Co $2 p$ spectrum (Fig. 1c) shows peaks at 778.5 and $793.6 \mathrm{eV}$ assigned to cobalt sulfide in the composite, with peaks at 781.0 and $796.5 \mathrm{eV}$ mainly attributed to cobalt oxide species, which is originated from the partial oxidation on the surface of composite [45-47]. In the S 2p spectrum (Fig. 1d), a spin-orbit doublet at $161.3 / 162.5 \mathrm{eV}$ is found due to the presence of $\mathrm{S}^{2-}$. Other peaks are observed at 162.4/163.6 eV corresponding to $\mathrm{S}_{\mathrm{n}}{ }^{2-}$, and $167.6 / 168.8 \mathrm{eV}$ belong to $\mathrm{SO}_{\mathrm{x}}$ from the partial superficial oxidation of the composite $[9,10]$. The high-resolution $N$ 1s spectrum (Figure 1e) is deconvoluted into five peaks at 398.5, 399.5, 400.3, 401.3 and $403.3 \mathrm{eV}$, which are assigned to pyridinic- $\mathrm{N}$, amino- $\mathrm{N}$, pyrrolic- $\mathrm{N}$, graphitic- $\mathrm{N}$ and oxidized- $\mathrm{N}$, respectively. In addition, the high pyridinic- $\mathrm{N}$ and pyrrolic- $\mathrm{N}$ content is likely to provide more active sites for lithium and sodium storage $[22,48]$. In the high-resolution C 1 s spectrum (Figure 1f), peaks at 284.6 and $285.4 \mathrm{eV}$ from $\mathrm{sp}^{2}$ and $\mathrm{sp}^{3} \mathrm{C}-\mathrm{C}$ indicate both graphitic and amorphous states in the carbon structure, respectively. The peak at $285.9 \mathrm{eV}$ reveals the existence of C-N bonding, with peaks at 286.9 and $289.1 \mathrm{eV}$ corresponding to the $\mathrm{C}-\mathrm{O}$ and $\mathrm{C}=\mathrm{O}$, respectively $[49,50]$. The surface elemental Co, $S, N$ and $C$ contents of $\mathrm{Cog}_{9} \mathrm{~S}_{8} / \mathrm{HNCS}$ composite are quantified from XPS, with 3.85 atom\% cobalt, 3.41 atom\% sulfur, 9.50 atom\% nitrogen and 83.24 atom\% carbon. The obtained atom ratio of $\mathrm{Co} / \mathrm{S}$ corroborates the chemical formula of $\mathrm{Co}_{9} \mathrm{~S}_{8}$. In addition, the high content of nitrogen element on the surface of $\mathrm{Co}_{9} \mathrm{~S}_{8} / \mathrm{HNCS}$ composite reveals the high nitrogen doping in the PDA derived carbon shells. 

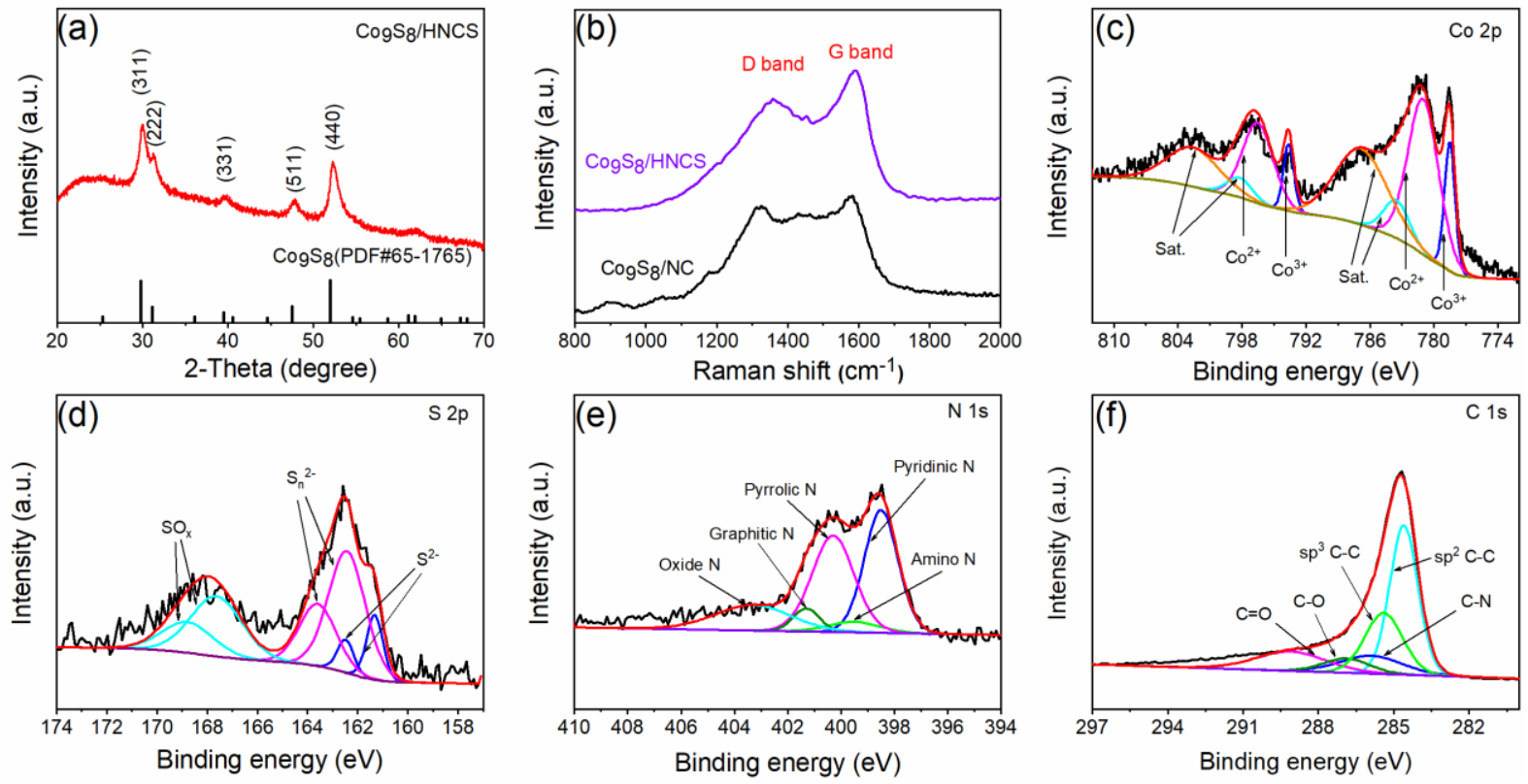

Fig. 1. (a) XRD pattern of the $\mathrm{Co}_{9} \mathrm{~S}_{8} / \mathrm{HNCS}$ composite. (b) Raman spectra of the $\mathrm{Cog}_{9} \mathrm{~S}_{8} / \mathrm{HNCS}$ and $\mathrm{Co}_{9} \mathrm{~S}_{8} / \mathrm{NC}$ composite. High-resolution XPS Co $2 \mathrm{p}$ spectrum (c), S $2 \mathrm{p}$ spectrum (d), N 1s spectrum (e) and C 1s spectrum ( $f$ ) of the $\mathrm{Co}_{9} \mathrm{~S}_{8} / \mathrm{HNCS}$ composite.

The morphology of as-prepared composites is examined using scanning electron microscopy (SEM), atomic-force microscopy (AFM) and transmission electron microscopy (TEM). Highly uniform $\mathrm{Co}_{9} \mathrm{~S}_{8} / \mathrm{HNCS}$ polyhedrons with an average size of $900 \pm 100 \mathrm{~nm}$ are shown in Fig. 2a. The high-resolution SEM images (Fig. 2b and c) clearly displayed a typical hollow rhombic-dodecahedron morphology, originating from the structure of the hollow PDA@ZIF-67 intermediates. Moreover, the energy dispersive X-Ray spectrum (EDS) of $\mathrm{Co}_{9} \mathrm{~S}_{8} / \mathrm{HNCS}$ composite (Fig. S9) indicates the existences of carbon, oxygen, nitrogen, sulfur and cobalt. In contrast, the SEM images of $\mathrm{Co}_{9} \mathrm{~S}_{8} / \mathrm{NC}$ composite (Fig. S10a, b) shows no obvious polyhedral structure, revealing that the initial structure of the ZIF-67 crystals is destroyed without PDA modification. The EDS of $\mathrm{Co}_{9} \mathrm{~S}_{8} / \mathrm{NC}$ composite (Fig. S10c) exhibits the expected elements $(\mathrm{C}, \mathrm{O}, \mathrm{N}, \mathrm{S}$ and $\mathrm{Co}$ ). It is noteworthy that the nitrogen content in $\mathrm{Co}_{9} \mathrm{~S}_{8} / \mathrm{HNCS}$ (12.60 atom\%) is much higher than that in $\mathrm{Co}_{9} \mathrm{~S}_{8} / \mathrm{NC}$ (4.12 atom\%), which is close to the calculated value $(9.50 \%)$ of XPS data of $\mathrm{Co}_{9} \mathrm{~S}_{8} / \mathrm{HNCS}$. More nitrogen doping in the $\mathrm{Co}_{9} \mathrm{~S}_{8} / \mathrm{HNCS}$ composite could promote electronic conductivity and generate more defects in the carbon layers, supplying more active sites for the lithium and sodium ion insertion $[22,23]$. The surface micromorphology of a single $\mathrm{Co}_{9} \mathrm{~S}_{8} / \mathrm{HNCS}$ particle is further characterized by AFM (Fig. 2d) exhibiting polyhedral structure. The height of the $\mathrm{Co}_{9} \mathrm{~S}_{8} / \mathrm{HNCS}$ 
particle is $780 \mathrm{~nm}$ on the central platform and $856 \mathrm{~nm}$ on the apex, further confirming the obtained rhombic-dodecahedron structure, in good agreement with the SEM results (Fig. 2a, $b$ and $c)$.
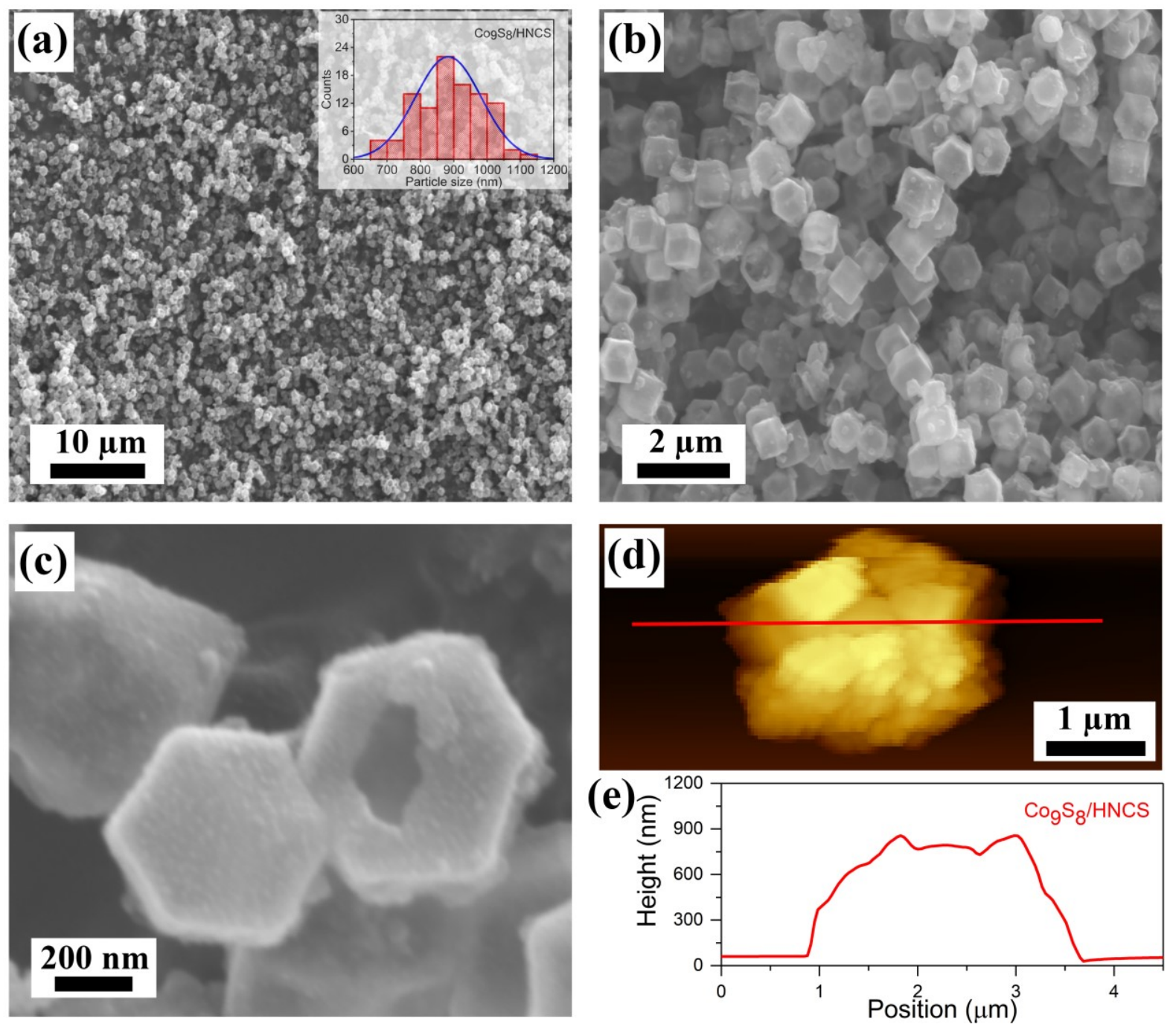

5 Fig. 2. (a, b, c) SEM images of the $\mathrm{Co}_{9} \mathrm{~S}_{8} / \mathrm{HNCS}$ composite; inset in (a) shows the particle size distribution. (d) AFM image of a single $\mathrm{Co}_{9} \mathrm{~S}_{8} / \mathrm{HNCS}$ nanoparticle; (e) height profile of the single $\mathrm{Co}_{9} \mathrm{~S}_{8} / \mathrm{HNCS}$ nanoparticle, indicated by the red line in (d).

TEM images of $\mathrm{Co}_{9} \mathrm{~S}_{8} / \mathrm{HNCS}$ (Fig. 3a and b) clearly show ultrafine and monodisperse $\mathrm{Co}_{9} \mathrm{~S}_{8}$ nanoparticles (Fig. 3a) with a size of $11 \pm 2 \mathrm{~nm}$ encapsulated in PDA derived carbon layers. Moreover, the dark boundary and bright center of the polyhedral shell emphasize the hollow structure. As a control, TEM images of $\mathrm{Co}_{9} \mathrm{~S}_{8} / \mathrm{NC}$ (Fig. S11) show $\mathrm{Co}_{9} \mathrm{~S}_{8}$ nanoparticles coated on the carbon layers with a fragmentized morphology. It is clear that the introduction of PDA in the ZIF-67 precursors leads to the generation of a novel hollow 
structure, as well as maintains polyhedral morphology during the carbonization and sulfurization. Fig. $3 \mathrm{~b}$ displays the porous structure of the composite and the wrapping of $\mathrm{Co}_{9} \mathrm{~S}_{8}$ nanoparticles in the polyhedral carbon framework. High-resolution TEM (Fig. 3c) further confirms that $\mathrm{Co}_{9} \mathrm{~S}_{8}$ nanoparticles embed in the carbon layers rather than attach on 5 the carbon outer surface. Lattice fringes estimated as $0.29 \mathrm{~nm}$ (Fig. 3c) are assigned to the (311) plane of $\mathrm{Co}_{9} \mathrm{~S}_{8}$ (JCPDS no. 65-1765) [51, 52]. The nanoscale elemental distribution within the composite structure is investigated with scanning-TEM and EDS mapping (Fig. S12). A line plot across a single $\mathrm{Co}_{9} \mathrm{~S}_{8} / \mathrm{HNCS}$ particle (Fig. 3d) and elemental maps (Fig. 3f-i) clearly shows a hollow framework of Co and S wrapped in a thin nitrogen-doped carbon matrix $(\mathrm{C}, \mathrm{N})$. $\mathrm{Co}, \mathrm{S}, \mathrm{N}$ and $\mathrm{C}$ elements are uniformly distributed in the polyhedral shell. 

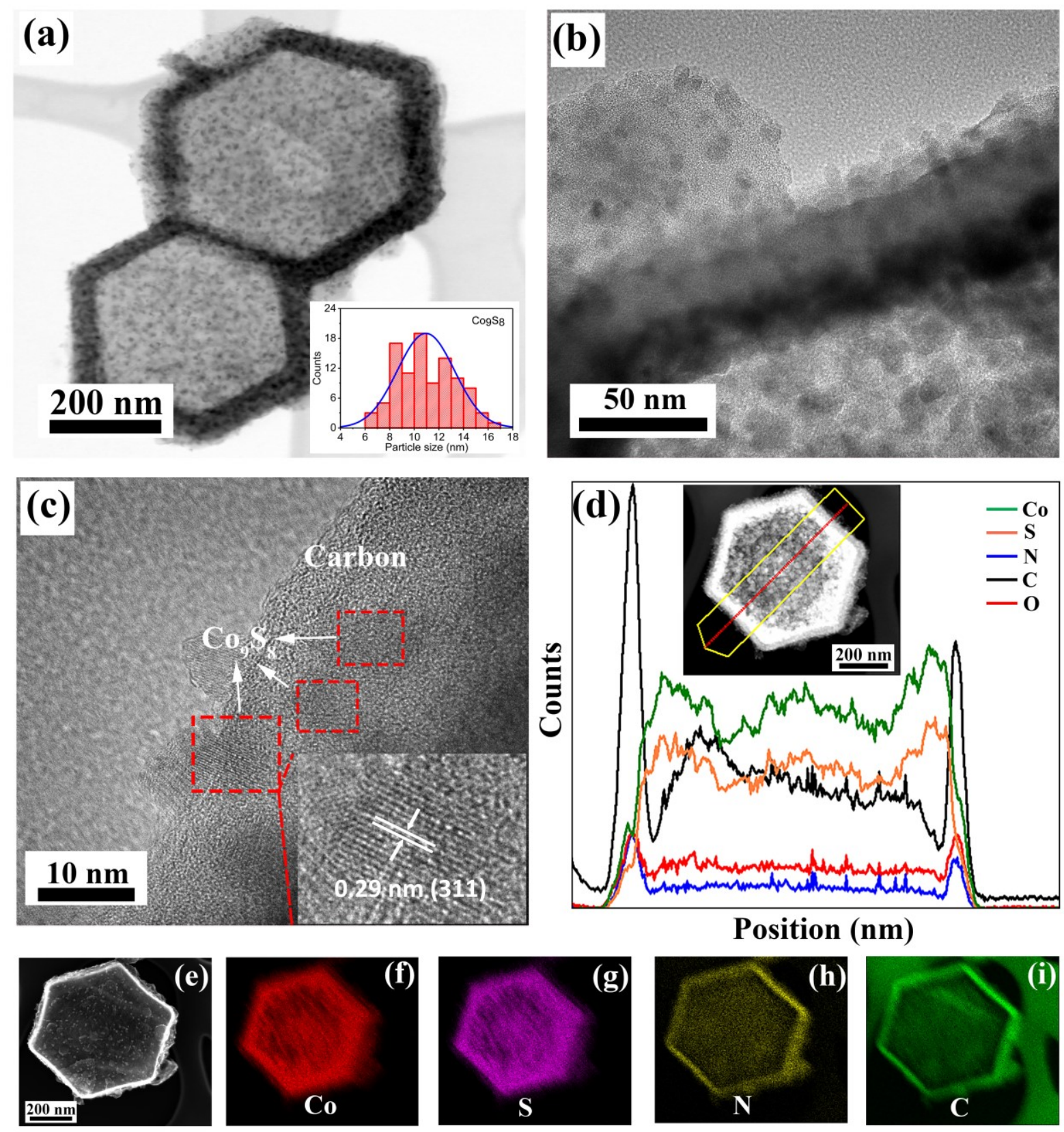

Fig. 3. (a) TEM image of the $\mathrm{Co}_{9} \mathrm{~S}_{8} / \mathrm{HNCS}$ composite; inset is the corresponding particle size distribution of $\mathrm{Co}_{9} \mathrm{~S}_{8}$ particles. (b) TEM image of the shell of the $\mathrm{Co}_{9} \mathrm{~S}_{8} / \mathrm{HNCS}$ composite. (c) High-resolution TEM image of the $\mathrm{Co}_{9} \mathrm{~S}_{8} / \mathrm{HNCS}$ composite. (d) Elemental distribution obtained from a line plot across a single $\mathrm{Co}_{9} \mathrm{~S}_{8} / \mathrm{HNCS}$ particle; Inset shows the line with the particle. (e) Secondary electron image, and (f-i) EDS elemental map of a single $\mathrm{Co}_{9} \mathrm{~S}_{8} / \mathrm{HNCS}$ particle.

Surface area and composition analysis of $\mathrm{Co}_{9} \mathrm{~S}_{8} / \mathrm{HNCS}$. Typical nitrogen adsorptiondesorption isotherms of as-prepared composites are shown in Fig. 4. The specific surface area of the $\mathrm{Co}_{9} \mathrm{~S}_{8} / \mathrm{HNCS}$ composite is $63.5 \mathrm{~m}^{2} \mathrm{~g}^{-1}$, while the $\mathrm{Co}_{9} \mathrm{~S}_{8} / \mathrm{NC}$ composite only 
registers a value of $24.6 \mathrm{~m}^{2} \mathrm{~g}^{-1}$. The inset in Fig. 4a present the pore-size distribution of $\mathrm{Co}_{9} \mathrm{~S}_{8} / \mathrm{HNCS}$ in the range of $23-95 \mathrm{~nm}$. This observation reveals that abundant mesopores (2$50 \mathrm{~nm}$ ) and macropores (> $50 \mathrm{~nm}$ ) simultaneously exist in the composite, most likely originating from the stacking of $\mathrm{Co}_{9} \mathrm{~S}_{8}$ nanoparticles and the hollow interior structure, respectively. In contrast, the pore size of $\mathrm{Co}_{9} \mathrm{~S}_{8} / \mathrm{NC}$ composite (Fig. 4b) distributes at about $32 \mathrm{~nm}$ and no obvious macropores are found. The components of synthesized composites are investigated by thermal gravimetric analysis (TGA) in air. A typical TGA curve of $\mathrm{Co}_{9} \mathrm{~S}_{8} / \mathrm{HNCS}$ composite (Fig. S13a) shows a weight loss below $150{ }^{\circ} \mathrm{C}$, attributed to the removal of adsorbed $\mathrm{H}_{2} \mathrm{O}$ and gaseous components in the composites. A weight increase is observed up to $320^{\circ} \mathrm{C}$, due to the partial formation of cobalt sulfate [53]. A rapid loss in the range of $320-550{ }^{\circ} \mathrm{C}$ is mainly attributed to the oxidation of carbon species. A constant platform in the region of $550-700{ }^{\circ} \mathrm{C}$ is ascribed to the balance from decomposition of carbon materials and generation of cobalt sulfate. A dramatic weight loss then occurs from 700-850 ${ }^{\circ} \mathrm{C}$, revealing the formation of $\mathrm{CO}_{3} \mathrm{O}_{4}$. Above $850{ }^{\circ} \mathrm{C}$, the weight remains constant. The total weight loss in the TGA curve of $\mathrm{Co}_{9} \mathrm{~S}_{8} / \mathrm{HNCS}$ composite (Fig. S13a) is about $49.6 \%$, indicating the percentage of cobalt sulfide to be $54.9 \%$. As a control, TGA of the $\mathrm{Co}_{9} \mathrm{~S}_{8} / \mathrm{NC}$ composite (Fig. S13b) provides a total weight loss of $29.2 \%$, and a cobalt sulfide content of 77.1\%. TGA of $\mathrm{Co}_{9} \mathrm{~S}_{8} / \mathrm{NC}$ (Fig. S13b) does not provide a visible weight loss from carbon as the region $320-550{ }^{\circ} \mathrm{C}$. This is different from that of $\mathrm{Co}_{9} \mathrm{~S}_{8} / \mathrm{HNCS}$, which is due to the weight increase from sulfide to sulfate over the weight loss from carbon dominates in the $\mathrm{Co}_{9} \mathrm{~S}_{8} / \mathrm{NC}$ composite. 

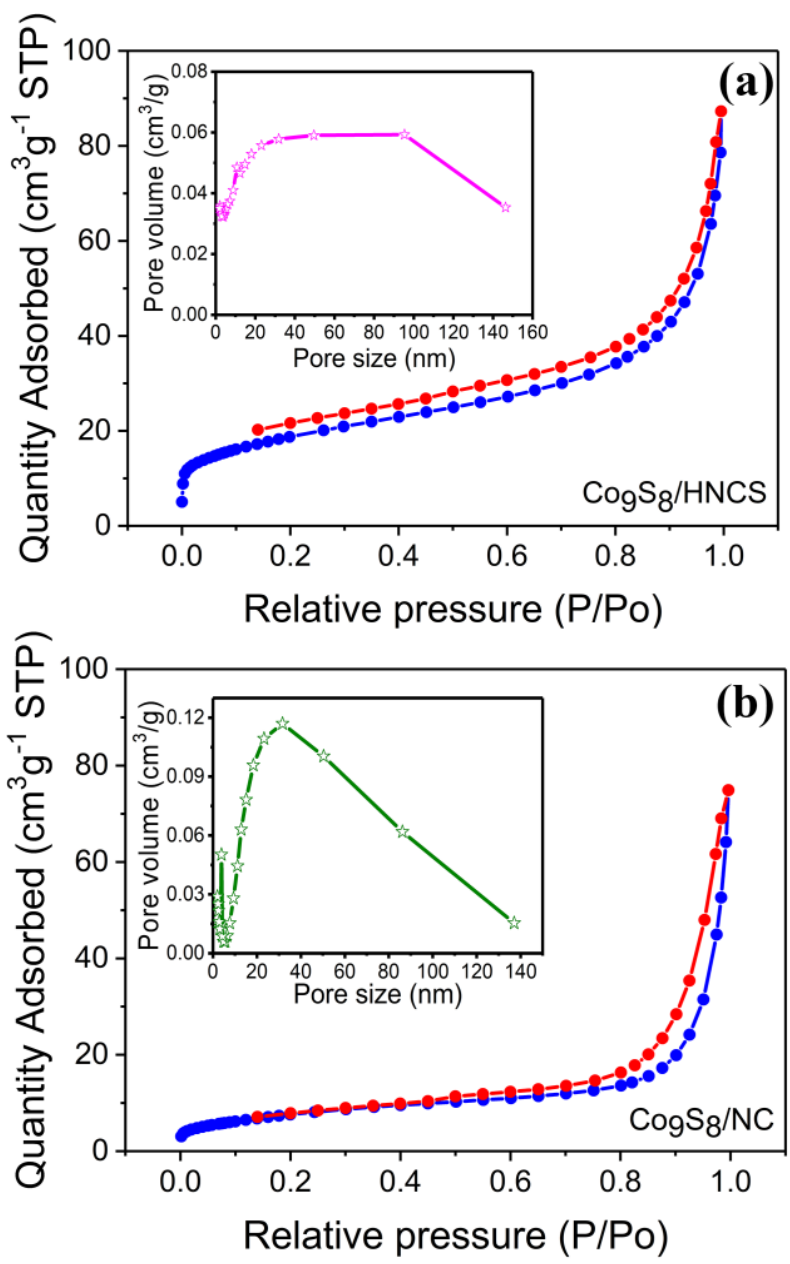

Fig. 4. Typical nitrogen adsorption-desorption isotherms of the $\mathrm{Co}_{9} \mathrm{~S}_{8} / \mathrm{HNCS}(\mathrm{a})$ and $\mathrm{Co}_{9} \mathrm{~S}_{8} / \mathrm{NC}$ (b) composite; Insets were the corresponding pore-size distribution.

Lithium storage performance. The lithium storage properties of $\mathrm{Co}_{9} \mathrm{~S}_{8} / \mathrm{HNCS}$ and $\mathrm{Co}_{9} \mathrm{~S}_{8} / \mathrm{NC}$ composites were evaluated in coin-type half cells. Cyclic voltammograms (CVs) of the first five cycles of $\mathrm{Co}_{9} \mathrm{~S}_{8} / \mathrm{HNCS}$ composite in a potential window of 0.01-3.0 V are demonstrated in Fig. 5a. Two peaks at ca. 1.0 and $0.40 \mathrm{~V}$ are found in the initial cathodic cycle, respectively. The peak at $1.0 \mathrm{~V}$ is assigned to the conversion of $\mathrm{Li}_{2} \mathrm{~S}$ and metallic cobalt, while the peak at $0.40 \mathrm{~V}$ is attributed to the formation of solid electrolyte interphase (SEI) film and partial decomposition of the electrolyte $[12,54]$. In the initial anodic cycle, a peak at about $2.1 \mathrm{~V}$ is clearly observed, corresponding to the sulfurization of metallic cobalt [12]. The conversional reaction can be described as following:

$\mathrm{Co}_{9} \mathrm{~S}_{8}+16 \mathrm{Li}^{+}+16 \mathrm{e}^{-} \leftrightarrow 8 \mathrm{Li}_{2} \mathrm{~S}+9 \mathrm{Co}$ 
After the first two scans, the cathodic peak and anodic peak shift to 1.1 and $2.5 \mathrm{~V}$, respectively. Moreover, the well-overlapping CVs after the first cycle reveal considerable electrochemical reversibility and stability of $\mathrm{Co}_{9} \mathrm{~S}_{8} / \mathrm{HNCS}$ composite. Differently, the CVs of $\mathrm{Co}_{9} \mathrm{~S}_{8} / \mathrm{NC}$ composite (Fig. S14a) decrease irreversible, indicating instability of $\mathrm{Co}_{9} \mathrm{~S}_{8} / \mathrm{NC}$ composite during cycling. Galvanostatic discharge/charge profiles of the first three, $10^{\text {th }}$ and $20^{\text {th }}$ cycles of $\mathrm{Co}_{9} \mathrm{~S}_{8} / \mathrm{HNCS}$ at a current density of $100 \mathrm{~mA} \mathrm{~g}^{-1}$ are shown in Fig. $5 \mathrm{~b}$. The observed voltage platforms in the first three cycles correspond to the peaks found in the $\mathrm{CVs}$ of $\mathrm{Co}_{9} \mathrm{~S}_{8} / \mathrm{HNCS}$. A small decrease of discharge and charge capacities is found in the $10^{\text {th }}$ and $20^{\text {th }}$ cycles, revealing considerable cycling stability. In comparison, the $\mathrm{Co}_{9} \mathrm{~S}_{8} / \mathrm{NC}$ (Fig. S14b) demonstrates a non-overlapping curve, indicating a poor cycling stability of $\mathrm{Co}_{9} \mathrm{~S}_{8} / \mathrm{NC}$ during cycling.

Fig. $5 c$ shows the cycling performance of the $\mathrm{Co}_{9} \mathrm{~S}_{8} / \mathrm{HNCS}$ and $\mathrm{Co}_{9} \mathrm{~S}_{8} / \mathrm{NC}$ composites at a current density of $100 \mathrm{~mA} \mathrm{~g}^{-1}$. The first discharge and charge capacities of $\mathrm{Co}_{9} \mathrm{~S}_{8} / \mathrm{HNCS}$ are 1105 and $879 \mathrm{~mA} \mathrm{~h} \mathrm{~g}^{-1}$, respectively, with an initial Coulombic efficiency of $80 \%$. The irreversible capacity loss (i.e. the lower initial charge capacity than the initial discharge capacity), is likely due to the irreversible consumption of $\mathrm{Li}^{+}$from side reaction with the electrolyte, partially irreversible $\mathrm{Li}^{+}$trapping in the amorphous carbon of the composite, and generation of the SEI film as a considerable amount of $\mathrm{Li}^{+}$irreversibly reacted with the surface of active materials $[12,54,55]$. The formation of SEI film has been identified by TEM images (Fig. S20c and d), which clearly show that the surface of the active material is coated by a SEl film after discharge-charge cycling. In contrast, $\mathrm{Co}_{9} \mathrm{~S}_{8} / \mathrm{NC}$ delivers an initial discharge/charge capacity of 1140/814 mA h g ${ }^{-1}$, with a lower initial Coulombic efficiency of $71 \%$. $\mathrm{Co}_{9} \mathrm{~S}_{8} / \mathrm{HNCS}$ maintains a stable discharge capacity of $768 \mathrm{~mA} \mathrm{~h} \mathrm{~g}^{-1}$ at $100 \mathrm{~mA} \mathrm{~g}^{-1}$ after 100 cycles, with a retained capacity of $70 \%$. The Coulombic efficiency is over $97 \%$ after the first three cycles. The good cycling stability of $\mathrm{Co}_{9} \mathrm{~S}_{8} / \mathrm{HNCS}$ is attributed to the integral structural stability of $\mathrm{Co}_{9} \mathrm{~S}_{8} / \mathrm{HNCS}$ with PDA derived carbon-shells modification. In converse, $\mathrm{Co}_{9} \mathrm{~S}_{8} / \mathrm{NC}$ shows a rapid capacity loss in discharge capacity and only delivers $345 \mathrm{~mA} \mathrm{~h} \mathrm{~g}^{-1}$ at $100 \mathrm{~mA} \mathrm{~g}^{-1}$ after 100 cycles, with a lower retained capacity of $30 \%$. The rate capabilities of $\mathrm{Co}_{9} \mathrm{~S}_{8} / \mathrm{HNCS}$ and $\mathrm{Co}_{9} \mathrm{~S}_{8} /$ NC composites at different current densities are shown in Fig. $5 \mathrm{~d}$. $\mathrm{Co}_{9} \mathrm{~S}_{8} / \mathrm{HNCS}$ (Fig.5d) delivers the first discharge/charge capacity of $1171 / 798 \mathrm{~mA} \mathrm{~h} \mathrm{~g}^{-1}$. In comparison, the initial discharge and charge capacities of $\mathrm{Co}_{9} \mathrm{~S}_{8} / \mathrm{NC}$ (Fig.5d) are 1140 and 
$632 \mathrm{~mA} \mathrm{~h} \mathrm{~g}{ }^{-1}$, respectively. The higher initial Coulombic efficiency (Fig. $5 \mathrm{c}$ and d) of $\mathrm{Co}_{9} \mathrm{~S}_{8} / \mathrm{HNCS}$ than $\mathrm{Co}_{9} \mathrm{~S}_{8} / \mathrm{NC}$ indicates that $\mathrm{Co}_{9} \mathrm{~S}_{8}$ nanoparticles locked in the hollow PDA derived carbon shells, and the higher nitrogen-doping level in the $\mathrm{Co}_{9} \mathrm{~S}_{8} / \mathrm{HNCS}$ composite can efficiently improve the integral electrical conductivity of the composite for $\mathrm{Li}^{+}$transport and significantly prevent detrimental reactions between active materials and electrolyte. Thus, the extent of first-cycle irreversible capacity loss of $\mathrm{Co}_{9} \mathrm{~S}_{8} / \mathrm{HNCS}$ is reduced $[17,22]$. In addition, $\mathrm{Co}_{9} \mathrm{~S}_{8} / \mathrm{HNCS}$ delivers discharge capacities of 734, 613, 579, 539, 447, $287 \mathrm{~mA} \mathrm{~h} \mathrm{~g}^{-1}$ at $100,200,300,500,1000,2000 \mathrm{~mA} \mathrm{~g}^{-1}$, respectively. Remarkably, setting the current density back to $100 \mathrm{~mA} \mathrm{~g}^{-1}$ after the $60^{\text {th }}$ cycle, the discharge capacity of $\mathrm{Co}_{9} \mathrm{~S}_{8} / \mathrm{HNCS}$ composite shows a stable performance and regains a value of $734 \mathrm{~mA} \mathrm{~h} \mathrm{~g}^{-1}$ after 90 cycles, suggesting an excellent rate capability originated from the structural stability of $\mathrm{Co}_{9} \mathrm{~S}_{8} / \mathrm{HNCS}$ during cycling. In contrast, $\mathrm{Co}_{9} \mathrm{~S}_{8} / \mathrm{NC}$ composite registers discharge capacities of 518,323 , 216, 146, 96, $65 \mathrm{~mA} \mathrm{~h} \mathrm{~g}^{-1}$ at 100, 200, 300, 500, 1000, $2000 \mathrm{~mA} \mathrm{~g}^{-1}$, respectively. Upon resetting the current density to $100 \mathrm{~mA} \mathrm{~g}^{-1}$, the discharge capacity of $\mathrm{Co}_{9} \mathrm{~S}_{8} / \mathrm{NC}$ composite decreases to $204 \mathrm{~mA} \mathrm{~h} \mathrm{~g}^{-1}$ after 90 cycles upon resetting current density to $100 \mathrm{~mA} \mathrm{~g}^{-1}, 39 \%$ of the initial capacity $\left(518 \mathrm{~mA} \mathrm{~h} \mathrm{~g}^{-1}\right)$. The results indicate the $\mathrm{Co}_{9} \mathrm{~S}_{8} / \mathrm{NC}$ composite without PDA modification cannot buffer the large volume expansion during high-rate cycling, leading to a poor rate performance. 

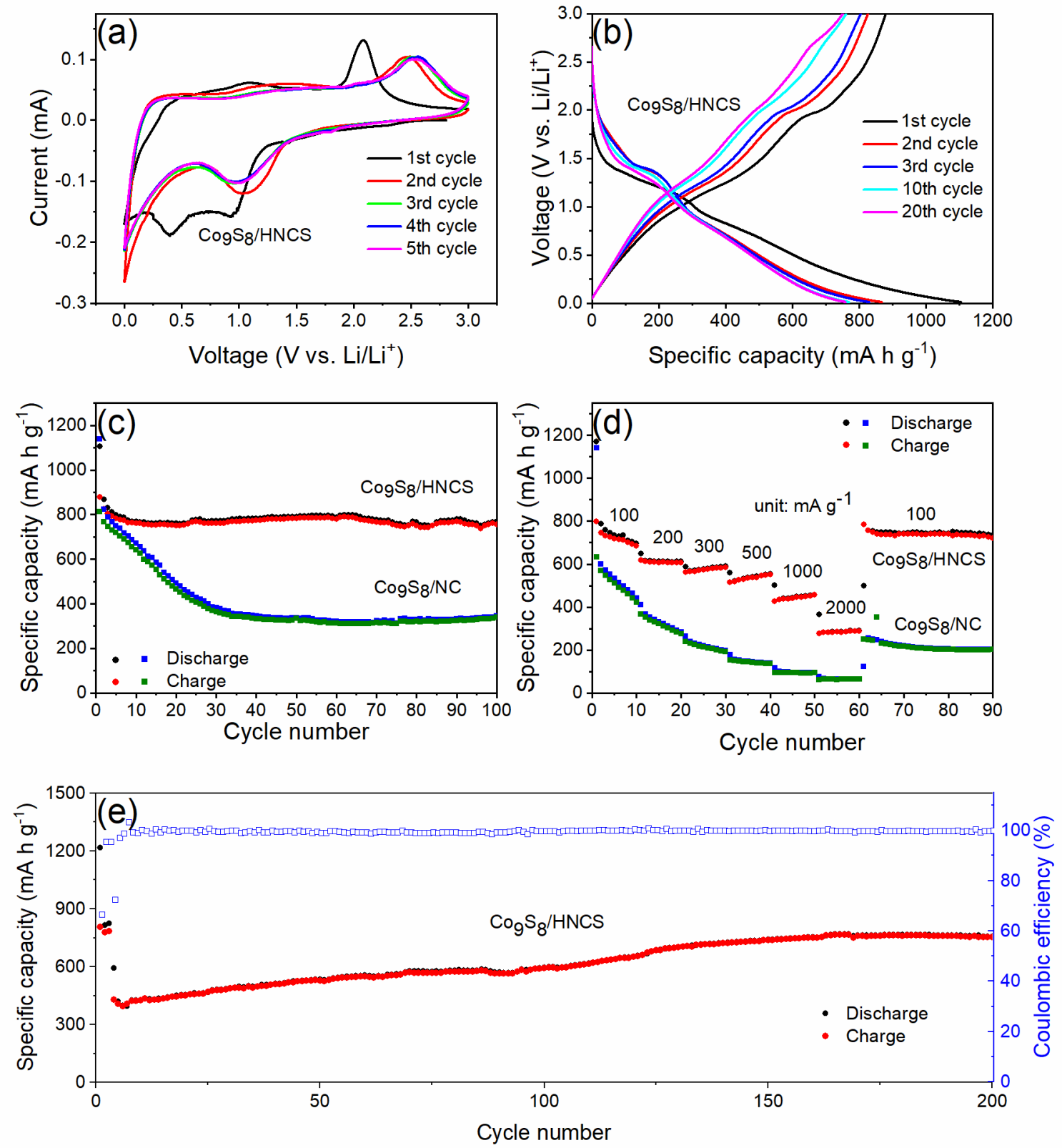

Fig. 5. Electrochemical behavior of as-prepared composites for lithium ion storage: (a) Cyclic voltammograms of the first five cycles of $\mathrm{Co}_{9} \mathrm{~S}_{8} / \mathrm{HNCS}$ composite with a scann rate of $0.1 \mathrm{mV}$ $\mathrm{s}^{-1}$. (b) Galvanostatic discharge/charge profiles of the first three, $10^{\text {th }}$ and $20^{\text {th }}$ cycles of $5 \mathrm{Co}_{9} \mathrm{~S}_{8} / \mathrm{HNCS}$ composite at a current density of $100 \mathrm{~mA} \mathrm{~g}^{-1}$. (c) Cycling performance of the $\mathrm{Co}_{9} \mathrm{~S}_{8} / \mathrm{HNCS}$ and $\mathrm{Cog}_{9} \mathrm{~S}_{8} / \mathrm{NC}$ composites at a current density of $100 \mathrm{~mA} \mathrm{~g}^{-1}$. (d) Rate capabilities at different current densities. (e) Cycling performance of $\mathrm{Co}_{9} \mathrm{~S}_{8} / \mathrm{HNCS}$ composite at a high current density of $500 \mathrm{~mA} \mathrm{~g}^{-1}$ after cycling with first three cycles at $100 \mathrm{~mA} \mathrm{~g}^{-1}$.

Fig. 5e displays the cycling performance of $\mathrm{Co}_{9} \mathrm{~S}_{8} / \mathrm{HNCS}$ composite at a high current 10 density of $500 \mathrm{~mA} \mathrm{~g}^{-1}$ after discharge-charge cycling with first three cycles at $100 \mathrm{~mA} \mathrm{~g}^{-1}$. The 
initial discharge and charge capacities are 1217 and $806 \mathrm{~mA} \mathrm{~h} \mathrm{~g}^{-1}$, respectively, with a low initial Coulombic efficiency of $66 \%$. Besides, $\mathrm{Co}_{9} \mathrm{~S}_{8} / \mathrm{HNCS}$ shows the low Coulombic efficiencies during first four cycles, which are attributed to the partial decomposition of the electrolyte and activation process of electrode materials during the low current density of $100 \mathrm{~mA} \mathrm{~g}^{-1}$. In addition, the low Coulombic efficiency of the forth cycle is mainly due to the change from the low current density $\left(100 \mathrm{~mA} \mathrm{~g}^{-1}\right)$ to the high current density $\left(500 \mathrm{~mA} \mathrm{~g}^{-1}\right)$, since the lithium ion requires time to complete insertion or extraction in the $\mathrm{Cog}_{9} \mathrm{~S}_{8} / \mathrm{HNCS}$ electrode materials. Then, the discharge capacity of $\mathrm{Co}_{9} \mathrm{~S}_{8} / \mathrm{HNCS}$ decreases to $428 \mathrm{~mA} \mathrm{~h} \mathrm{~g}^{-1}$ at the $13^{\text {th }}$ cycle. After that, the discharge capacity gradually increases and stabilizes at 755 $\mathrm{mA} \mathrm{h} \mathrm{g}^{-1}$ after 200 cycles, with a Coulombic efficiency of over $98 \%$. The unique behavior is ascribed to structural rearrangement of electrode materials due to long-term activation effects. In addition, it is noteworthy that the discharge capacity of $\mathrm{Co}_{9} \mathrm{~S}_{8} / \mathrm{HNCS}$ composite is higher than the theoretical specific capacity of $\mathrm{Co}_{9} \mathrm{~S}_{8}\left(544 \mathrm{~mA} \mathrm{~h} \mathrm{~g}^{-1}\right)$, which could be ascribed to the formation of electroactive polymeric gel-like film on the surface of hollow porous structure, as well as the insertion of lithium ions into interfacial storage [7, 44]. As a reference, the long-term cycle performance of $\mathrm{Co}_{9} \mathrm{~S}_{8} / \mathrm{NC}$ is tested under the same condition (Fig. S15). The discharge capacity of $\mathrm{Co}_{9} \mathrm{~S}_{8} / \mathrm{NC}$ composite only reaches $321 \mathrm{~mA} \mathrm{~h} \mathrm{~g}^{-1}$ after 200 cycles. Moreover, compared with previously reported cobalt sulfides based systems for lithium storage (Table S1), the $\mathrm{Co}_{9} \mathrm{~S}_{8} / \mathrm{HNCS}$ composite exhibits superior cycling stability and rate capability.

Sodium storage performance. To test the sodium storage of $\mathrm{Co}_{9} \mathrm{~S}_{8} / \mathrm{HNCS}$ and $\mathrm{Co}_{9} \mathrm{~S}_{8} / \mathrm{NC}$ composites, coin-type half-cells with metallic sodium as the counter electrode were assembled. Fig. 6a demonstrates the cyclic voltammograms (CVs) of the first five cycles of $\mathrm{Co}_{9} \mathrm{~S}_{8} / \mathrm{HNCS}$ in a voltage range of $0.01-3.0 \mathrm{~V}$ at $0.1 \mathrm{mV} \mathrm{s}^{-1}$. A main reductive peak at about $0.40 \mathrm{~V}$ is observed, revealing the conversion reaction of cobalt sulfide with sodium ion. Another small peak at about $0.90 \mathrm{~V}$ is ascribed to partial decomposition of the electrolyte and the formation of SEI film. The oxidative peak at about $1.75 \mathrm{~V}$ is ascribed to the oxidation of metallic Co $[15,56]$. The detailed electrochemical reaction could be shown as following [15]: 
Where $x=(n+m) / 2$. After the initial scans, the reductive and oxidative peaks shift to 0.84 and $1.78 \mathrm{~V}$, respectively. Moreover, the CVs overlap well in the subsequent cycles, indicating excellent cycling stability of the $\mathrm{Co}_{9} \mathrm{~S}_{8} / \mathrm{HNCS}$ composite for sodium ion storage. In comparison, the $\mathrm{CVS}$ of $\mathrm{Co}_{9} \mathrm{~S}_{8} / \mathrm{NC}$ composite (Fig. S16a) shows a continuous degenerative process from the first five cycles, revealing the instability of $\mathrm{Co}_{9} \mathrm{~S}_{8} / \mathrm{NC}$ during cycling. Fig. $6 \mathrm{~b}$ shows the galvanostatic discharge/charge profiles of the cycles 1-3, 10 and 20 of $\mathrm{Co}_{9} \mathrm{~S}_{8} / \mathrm{HNCS}$ at a current density of $100 \mathrm{~mA} \mathrm{~g}^{-1}$. The potential slopes found in the first three cycles agree with the peaks in the $\mathrm{CVs}$ of $\mathrm{Co}_{9} \mathrm{~S}_{8} / \mathrm{HNCS}$. The $\mathrm{Co}_{9} \mathrm{~S}_{8} / \mathrm{HNCS}$ registers the initial discharge and charge capacity of 713 and $368 \mathrm{~mA} \mathrm{~h} \mathrm{~g}^{-1}$, respectively. The relatively low Coulombic efficiency of $52 \%$ is attributed to generation of SEI film and partial decomposition of the electrolyte $[15,56]$. The lower initial Coulombic efficiency $(52 \%)$ of $\mathrm{Co}_{9} \mathrm{~S}_{8} / \mathrm{HNCS}$ for SIBs than that (80\%) for LIBs is mainly attributed to the larger ionic radius of sodium ion $(1.02 \AA)$ comparing to that of lithium ion $(0.76 \AA)$, resulting in more sluggish sodium ion diffusion kinetics than lithium ion. Good overlap is observed during the $10^{\text {th }}$ and $20^{\text {th }}$ cycles, confirming the superior cycling stability. Differently, the initial discharge and charge capacity of $\mathrm{Co}_{9} \mathrm{~S}_{8} / \mathrm{NC}$ composite (Fig. S16b) is 679 and $418 \mathrm{~mA} \mathrm{~h} \mathrm{~g}^{-1}$. Besides, no overlapping curves (Fig. S16b) are observed, implying inferior cycling stability.

The cycling performance of the $\mathrm{Co}_{9} \mathrm{~S}_{8} / \mathrm{HNCS}$ and $\mathrm{Co}_{9} \mathrm{~S}_{8} / \mathrm{NC}$ composites at a current density of $100 \mathrm{~mA} \mathrm{~g}^{-1}$ is showed in Fig. 6c. $\mathrm{Co}_{9} \mathrm{~S}_{8} / \mathrm{HNCS}$ shows a small capacity decrease during the first five cycles, with a discharge capacity of $372 \mathrm{~mA} \mathrm{~h} \mathrm{~g}{ }^{-1}$ of the fifth cycle. A gradual capacity increase (Fig. $6 \mathrm{c}$ ) is found after the $5^{\text {th }}$ cycle, indicating structural rearrangement of electrode materials originating from activation of the materials, which provides more active sites during cycling $[9,10]$. $\mathrm{Co}_{9} \mathrm{~S}_{8} / \mathrm{HNCS}$ delivers a stable discharge capacity of $421 \mathrm{~mA} \mathrm{~h} \mathrm{~g}^{-1}$ at $100 \mathrm{~mA} \mathrm{~g}^{-1}$ after 50 cycles, and a Coulombic efficiency above $96 \%$ after the first five cycles. In contrast, $\mathrm{Co}_{9} \mathrm{~S}_{8} / \mathrm{NC}$ exhibits a dramatic capacity decay and only retains a discharge capacity of $63 \mathrm{~mA} \mathrm{~h} \mathrm{~g}^{-1}$ at $100 \mathrm{~mA} \mathrm{~g}^{-1}$ after 50 cycles, with a lower retained capacity of $9 \%$. It is noteworthy that the obvious higher capacities (Fig. 6c) for $\mathrm{Co}_{9} \mathrm{~S}_{8} / \mathrm{NC}$ than that of $\mathrm{Co}_{9} \mathrm{~S}_{8} / \mathrm{HNCS}$ during the beginning several cycles are mainly attributed to the higher $\mathrm{Co}_{9} \mathrm{~S}_{8}$ ratio of $\mathrm{Co}_{9} \mathrm{~S}_{8} / \mathrm{NC}$ (77.1\%, Fig. S13a) than that of $\mathrm{Co}_{9} \mathrm{~S}_{8} / \mathrm{HNCS}$ (54.9\%, Fig. S13b). The results further indicate the high extent of utilization of active materials in the $\mathrm{Co}_{9} \mathrm{~S}_{8} / \mathrm{HNCS}$ electrode. Fig. $6 \mathrm{~d}$ displays the rate capabilities of the $\mathrm{Co}_{9} \mathrm{~S}_{8} / \mathrm{HNCS}$ and $\mathrm{Co}_{9} \mathrm{~S}_{8} / \mathrm{NC}$ composites at different 
current densities. $\mathrm{Co}_{9} \mathrm{~S}_{8} / \mathrm{HNCS}$ exhibits discharge capacities of 386, 340, 330, 311, 288, 252 $\mathrm{mA} \mathrm{h} \mathrm{g}{ }^{-1}$ assigning to current densities of 100, 200,300,500,1000, $2000 \mathrm{~mA} \mathrm{~g}^{-1}$, respectively. When the current density is reset $100 \mathrm{~mA} \mathrm{~g}^{-1}$ after 60 cycles, the discharge capacity of $\mathrm{Co}_{9} \mathrm{~S}_{8} / \mathrm{HNCS}$ restores to $394 \mathrm{~mA} \mathrm{~h} \mathrm{~g}^{-1}$ after 90 cycles with a good capacity retention, 5 indicating a promising rate capability. In contrast, the discharge capacities of $\mathrm{Co}_{9} \mathrm{~S}_{8} / \mathrm{NC}$ composite are $347,188,87,46,25,12 \mathrm{~mA} \mathrm{~h} \mathrm{~g}^{-1}$ at current densities of 100, 200, 300, 500, $1000,2000 \mathrm{~mA} \mathrm{~g}^{-1}$, respectively. $\mathrm{Co}_{9} \mathrm{~S}_{8} / \mathrm{NC}$ only delivers a discharge capacity of $62 \mathrm{~mA} \mathrm{~h} \mathrm{~g}{ }^{-1}$ after 90 cycles when reverting the current density to $100 \mathrm{~mA} \mathrm{~g}^{-1}$, showing a sharp capacity loss. The better rate performance of $\mathrm{Co}_{9} \mathrm{~S}_{8} / \mathrm{HNCS}$ is mainly attributed to the integral hollow nanostructure, which could provide more active sites and space for sodium ion insertion/extraction. Further, the hollow interior structure of $\mathrm{Co}_{9} \mathrm{~S}_{8} / \mathrm{HNCS}$ could offer extra inner void to accommodate large volume change during high current-density cycling. 

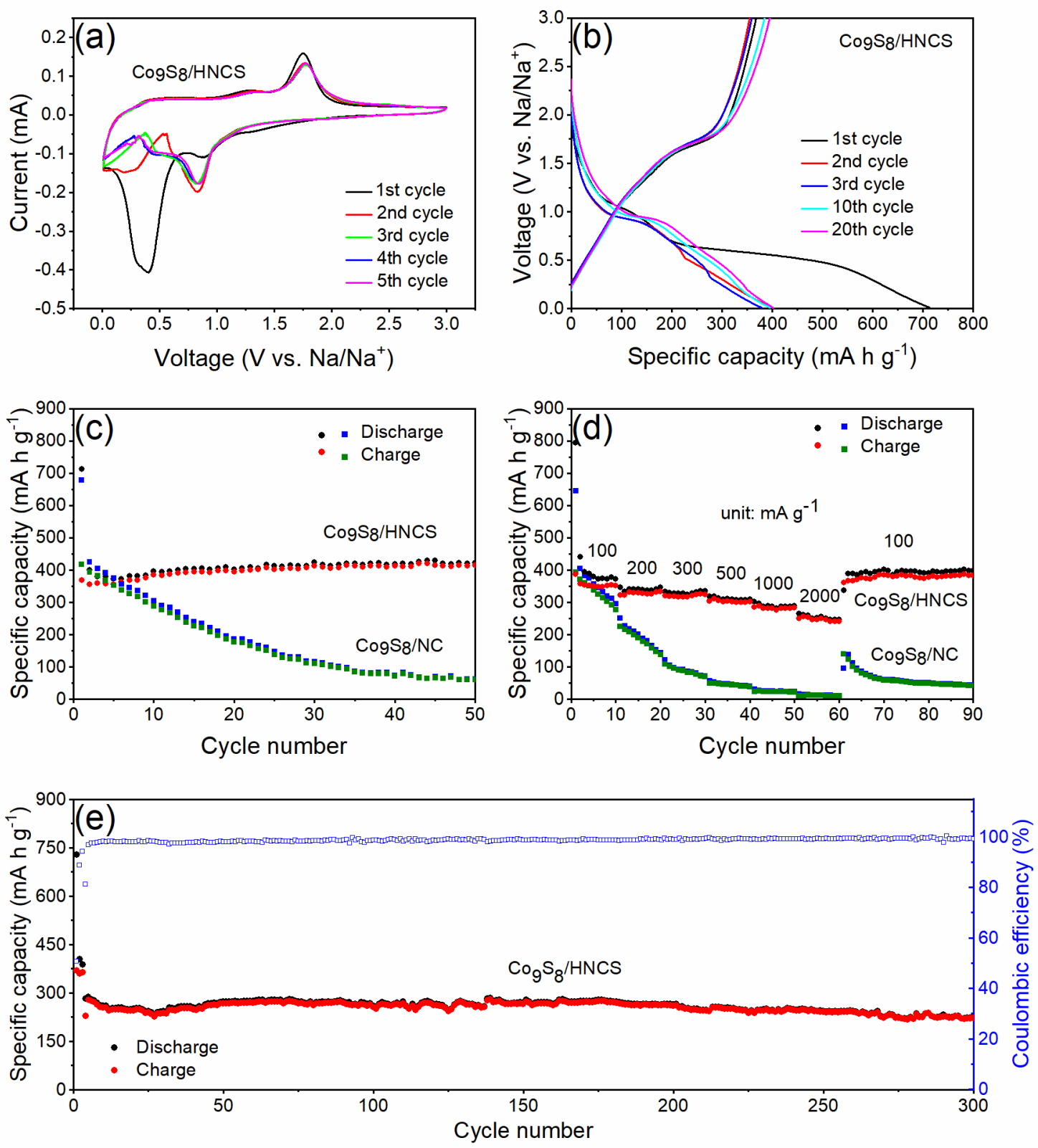

Fig. 6. Electrochemical behavior of as-prepared composites as sodium ion storage materials: (a) Cyclic voltammograms of the first five cycles of $\mathrm{Co}_{9} \mathrm{~S}_{8} / \mathrm{HNCS}$ composite at a scan rate of $0.1 \mathrm{mV} \mathrm{s}^{-1}$. (b) Galvanostatic discharge/charge profiles of the first three, $10^{\text {th }}$ and $20^{\text {th }}$ cycles 5 of $\mathrm{Co}_{9} \mathrm{~S}_{8} / \mathrm{HNCS}$ composite at a current density of $100 \mathrm{~mA} \mathrm{~g}^{-1}$. (c) Cycling performance of the $\mathrm{Co}_{9} \mathrm{~S}_{8} / \mathrm{HNCS}$ and $\mathrm{Co}_{9} \mathrm{~S}_{8} / \mathrm{NC}$ composites at a current rate of $100 \mathrm{~mA} \mathrm{~g}^{-1}$. (d) Rate capabilities at various current densities. (e) Cycling performance of the $\mathrm{Co}_{9} \mathrm{~S}_{8} / \mathrm{HNCS}$ composite at a current density of $1000 \mathrm{~mA} \mathrm{~g}^{-1}$ after cycling with first three cycles at $100 \mathrm{~mA} \mathrm{~g}^{-1}$.

Cycling performance of $\mathrm{Cog}_{9} \mathrm{~S}_{8} / \mathrm{HNCS}$ for sodium ion storage at high current densities of 500 and $1000 \mathrm{~mA} \mathrm{~g}^{-1}$ after discharge-charge cycling with the first three cycles at $100 \mathrm{~mA} \mathrm{~g}^{-1}$ 
is further studied. Fig. S17 shows that $\mathrm{Co}_{9} \mathrm{~S}_{8} / \mathrm{HNCS}$ registers a discharge capacity of $327 \mathrm{~mA}$ $\mathrm{h} \mathrm{g}^{-1}$ at $500 \mathrm{~mA} \mathrm{~g}^{-1}$ after 200 cycles, with a Coulombic efficiency of more than $97 \%$ after first fifth cycles. In contrast, $\mathrm{Co}_{9} \mathrm{~S}_{8} / \mathrm{NC}$ only demonstrates a discharge capacity of $26 \mathrm{~mA} \mathrm{~h} \mathrm{~g}^{-1}$ at $500 \mathrm{~mA} \mathrm{~g}^{-1}$ after 200 cycles. Fig. 6e shows the long-term cycling performance of $\mathrm{Co}_{9} \mathrm{~S}_{8} / \mathrm{HNCS}$ composite at $1000 \mathrm{~mA} \mathrm{~g}^{-1}$. The discharge capacity of $\mathrm{Co}_{9} \mathrm{~S}_{8} / \mathrm{HNCS}$ is initially $729 \mathrm{~mA} \mathrm{~h} \mathrm{~g}^{-1}$, and decreases to $231 \mathrm{~mA} \mathrm{~h} \mathrm{~g}{ }^{-1}$ after 27 cycles. After that, the discharge capacity gradually increases, and finally stabilizes and remains a discharge capacity of $224 \mathrm{~mA} \mathrm{~h} \mathrm{~g}^{-1}$ after 300 cycles. The Coulombic efficiency is over $97 \%$ after the first fifth cycles. Interestingly, Compared to the distinct increased capacity of $\mathrm{Co}_{9} \mathrm{~S}_{8} / \mathrm{HNCS}$ for lithium ion storage (Fig. 5e) at a high current density of $500 \mathrm{~mA} \mathrm{~g}^{-1}$, the $\mathrm{Co}_{9} \mathrm{~S}_{8} / \mathrm{HNCS}$ shows a relatively stable cyclic ability for sodium ion storage (Fig. 6e). This phenomenon could be mainly result from the larger ionic radius of sodium ion than that of lithium ion, leading to the decrease of sodiumions insertion into interfacial storage between the cobalt sulfide and hollow carbon shells [7, 10]. The $\mathrm{Co}_{9} \mathrm{~S}_{8} / \mathrm{NC}$ composite shows poor long-term cycling performance (Fig. S18) with a discharge capacity of only $19 \mathrm{~mA} \mathrm{~h} \mathrm{~g}{ }^{-1}$ after 300 cycles. In contrast to previous reports on cobalt sulfides related systems for sodium storage (Table S2), the $\mathrm{Co}_{9} \mathrm{~S}_{8} / \mathrm{HNCS}$ composite exhibits a promising sodium ion storage, which is attributed to the integral hollow structure associated with the uniform cobalt sulfide nanoparticles and nitrogen-doped carbon networks.

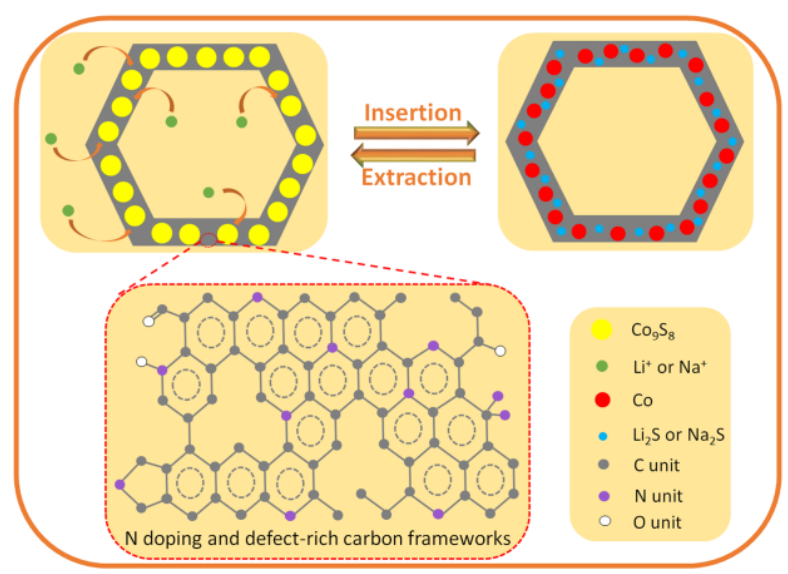

Scheme 2. Schematic illustration of the electrochemical process of $\mathrm{Co}_{9} \mathrm{~S}_{8} / \mathrm{HNCS}$ composite for lithium or storage ion storage. Not drawn to real scale.

To obtain a better understanding of the superior lithium and sodium ion storage properties of $\mathrm{Co}_{9} \mathrm{~S}_{8} / \mathrm{HNCS}$, electrochemical impedance spectroscopy (EIS) studies of the 
$\mathrm{Co}_{9} \mathrm{~S}_{8} / \mathrm{HNCS}$ and $\mathrm{Co}_{9} \mathrm{~S}_{8} / \mathrm{NC}$ composites as lithium and sodium ion storage materials before cycling and after the $1^{\text {st }}, 3^{\text {rd }}$ and $10^{\text {th }}$ cycles were performed (Fig. S19). The semicircle at medium frequency region corresponds to the charge-transfer resistance $\left(R_{c t}\right)$ between the electrolyte and electrode. The fitted $R_{\text {ct }}$ values are listed in Table S3. Fresh cells based on the $\mathrm{Cog}_{9} \mathrm{~S}_{8} / \mathrm{HNCS}$ composite (172 $\Omega$ for LIBs and $447 \Omega$ for SIBs) show lower $\mathrm{R}_{\mathrm{ct}}$ values than that of the $\mathrm{Co}_{9} \mathrm{~S}_{8} / \mathrm{NC}$ composite (400 $\Omega$ for LIBs and $915 \Omega$ for SIBs), indicating faster charge transfer kinetics for $\mathrm{CO}_{9} \mathrm{~S}_{8} / \mathrm{HNCS}$. This is attributed to the encapsulation effect of PDA derived carbon layers, which could cross-link monodisperse $\mathrm{Co}_{9} \mathrm{~S}_{8}$ nanoparticles to improve inter-particle connection of $\mathrm{Co}_{9} \mathrm{~S}_{8} / \mathrm{HNCS}$ for fast charge transfer. Besides, higher nitrogen doping level of $\mathrm{Co}_{9} \mathrm{~S}_{8} / \mathrm{HNCS}$ (12.60 atom\%, Fig. S9) over $\mathrm{Co}_{9} \mathrm{~S}_{8} / \mathrm{NC}$ (4.12 atom\%, Fig. S10c) is likely to decrease $R_{c t}$. This is because higher nitrogen-doping extent not only facilitates the electronic conductivity of carbon coating layer, but also enhances the interactions between the nitrogen-doped carbon structure and lithium or sodium ions [22, 23]. After the first cycle, $\mathrm{Co}_{9} \mathrm{~S}_{8} / \mathrm{HNCS}$ shows a relatively stable charge-transfer resistance (Fig. S19 a, c) compared with the $R_{c t}$ of fresh cells, in contrast, a large change of $R_{c t}$ value for $\mathrm{Co}_{9} \mathrm{~S}_{8} / \mathrm{NC}$ electrode (Fig. $\mathrm{S} 19 \mathrm{~b}, \mathrm{~d})$ after the initial cycle demonstrates the structural instability of the $\mathrm{Co}_{9} \mathrm{~S}_{8} / \mathrm{NC}$ materials. After the $3^{\text {rd }}$ and $10^{\text {th }}$ cycle, the $\mathrm{R}_{\mathrm{ct}}$ of $\mathrm{Co}_{9} \mathrm{~S}_{8} / \mathrm{HNCS}$ gradually levels off (Fig. S19 a, c and Table S3), due to the activation of the $\mathrm{Co}_{9} \mathrm{~S}_{8} / \mathrm{HNCS}$ electrode $[34,57]$. While, $\mathrm{Co}_{9} \mathrm{~S}_{8} / \mathrm{NC}$ (Fig. S19 b, $d$ and Table S3) exhibits increased $R_{c t}$, further confirming the structural fragmentation of $\mathrm{Co}_{9} \mathrm{~S}_{8} / \mathrm{NC}$ electrode during cycling. Moreover, the morphology and structural changes of $\mathrm{Cog}_{9} / \mathrm{HNCS}$ during lithium and sodium ion storage are also investigated. First, the cycled batteries for lithium storage were disassembled after 50 cycles at $100 \mathrm{~mA} \mathrm{~g}^{-1}$. SEM and TEM images (Fig. S20) show that the hollow structure with $\mathrm{Co}_{9} \mathrm{~S}_{8}$ nanoparticles embedded in the carbon matrix is maintained in the electrode materials after cycling, revealing excellent structural stability of the $\mathrm{Co}_{9} \mathrm{~S}_{8} / \mathrm{HNCS}$ composite during lithium ion insertion/extraction. Interestingly, the thick layer covering $\mathrm{Co}_{9} \mathrm{~S}_{8} / \mathrm{HNCS}$ formed after cycling in Fig. S20c and d is believed to be the solid electrolyte interphase (SEI) film. The thickness of SEI film is measured to be in the range of $100-120 \mathrm{~nm}$, which is comparable to the previous reports $[58,59]$. The stable SEI film could prevent the further decomposition of electrolyte and maintain effectively the structural stability of $\mathrm{Co}_{9} \mathrm{~S}_{8} / \mathrm{HNCS}$ during cycling for the promising electrochemical performance [58]. We also disassembled the cycled coin cells for sodium storage after 50 cycles at $100 \mathrm{~mA} \mathrm{~g}^{-1}$. No pulverization and aggregation (Fig. S21) 
were observed, and $\mathrm{Co}_{9} \mathrm{~S}_{8}$ nanoparticles are tightly interconnected by carbon layers during sodium ion insertion/extraction. These results were further demonstrated as illustrated in Scheme 2. The promising electrochemical performance of $\mathrm{Co}_{9} \mathrm{~S}_{8} / \mathrm{HNCS}$ for lithium and sodium storage could be regarded as the result of the combined effect of homogenously ultrafine $\mathrm{Co}_{9} \mathrm{~S}_{8}$ nanoparticles associated with hollow nitrogen-doped carbon polyhedral shells. Firstly, ultrafine $\mathrm{Co}_{9} \mathrm{~S}_{8}$ nanoparticles $(11 \pm 2 \mathrm{~nm}$ ) effectively shorten the diffusion distance during lithium or sodium insertion/extraction; the entire electrode can efficiently accommodate the strain generated from cycling due to the highly uniform $\mathrm{Cog}_{9} \mathrm{~S}_{8}$ nanoparticles, thus facilitating good rate capability and cycling performance. Secondly, the hollow nitrogen-doped carbon networks not only promote electronic conductivity and provide more active sites for lithium and sodium storage, but also play a critical role as a buffer for volume expansion maintaining the structural integrity during cycling. Thirdly, the encapsulation of monodispersed $\mathrm{Co}_{9} \mathrm{~S}_{8}$ nanoparticles in the nitrogen-doped carbon polyhedral shells prevent $\mathrm{Co}_{9} \mathrm{~S}_{8}$ nanoparticles from aggregation and pulverization. More importantly, the hollow structure provides extra interior space with abundant active sites and contact area between active material and electrolyte, enhancing lithium or sodium ion diffusion and conversional reaction for superior cyclic stability and rate capability.

\section{Conclusions}

Well-defined cobalt sulfide nanoparticles encapsulated in 3D hollow nitrogen-doped carbon shells $\left(\mathrm{Co}_{9} \mathrm{~S}_{8} / \mathrm{HNCS}\right)$ were successfully constructed by utilizing nitrogen doped carbon layers derived from PDA layers to wrap and interconnect the monodisperse cobalt sulfide nanoparticles $(11 \pm 2 \mathrm{~nm}$ ). The composite inherited the hollow polyhedral structure of the MOF (ZIF-67) skeleton. The remarkable synergistic effects between chemical and structural properties of the $\mathrm{Co}_{9} \mathrm{~S}_{8} / \mathrm{HNCS}$ composite give rise to superior electrochemical performance for lithium and sodium storage. As tested for lithium ion storage, $\mathrm{Co}_{9} \mathrm{~S}_{8} / \mathrm{HNCS}$ exhibits an impressive reversible capacity of $755 \mathrm{~mA} \mathrm{~h} \mathrm{~g}^{-1}$ at $500 \mathrm{~mA} \mathrm{~g}^{-1}$ after 200 cycles. When utilized for sodium ion storage, the $\mathrm{Co}_{9} \mathrm{~S}_{8} / \mathrm{HNCS}$ composite delivers superior capacities of $327 \mathrm{~mA} \mathrm{~h}$ $\mathrm{g}^{-1}$ at $500 \mathrm{~mA} \mathrm{~g}^{-1}$ after 200 cycles and $224 \mathrm{~mA} \mathrm{~h} \mathrm{~g}{ }^{-1}$ at $1000 \mathrm{~mA} \mathrm{~g}^{-1}$ after 300 cycles. These results highlight this composite as a promising electrode material for lithium and sodium 
storage. Moreover, the designed strategy of the $\mathrm{Co}_{9} \mathrm{~S}_{8} / \mathrm{HNCS}$ composite could be applied for other hollow metal sulfides for electrochemical energy conversion and storage technology.

\section{Appendix A. Supporting information}

Supplementary data associated with this article can be found in the online version.

\section{Declaration of interests}

The authors declare no competing financial interest.

\section{Acknowledgments}

Finance support from Shandong Provincial Science and Technology Major (2018JMRH0211, 2016GGX104001, 2017CXGC1010 and ZR2017MEM002), the Fundamental Research Funds of Shandong University (2016JC005, 2017JC042 and 2017JC010) and 1000 Talent Plan program (No. 31370086963030), Chinese Scholarship Council (201706220080), Danish

Council for Independent Research (DFT-1335-00330), H. C. Øersted COFUND fellowship, Independent Research Fund Denmark (DFF-5054-00107) are acknowledged. TEM work was partly performed at the UC Irvine Materials Research Institute (IMRI).

\section{References}

20 [1] M. Armand, J.-M. Tarascon, Building better batteries. Nature 451 (2008) 652-657.

[2] M. D. Slater, D. Kim, E. Lee, C. S. Johnson, Sodium-ion batteries. Adv. Funct. Mater. 23 (2013) 947-958.

[3] G. G. Amatucci, N. Pereira, Fluoride based electrode materials for advanced energy storage devices. J. Fluorine Chem. 128 (2007) 243-262.

25 [4] N. Yabuuchi, K. Kubota, M. Dahbi, S. Komaba, Research development on sodium-ion batteries. Chem. Rev. 114 (2014) 11636-11682.

[5] Y. Li, Y. Lu, C. Zhao, Y. -S. Hu, M. -M. Titirici, H. Li, X. Huang, L. Chen, Recent advances of electrode materials for low-cost sodium-ion batteries towards practical application for grid energy storage. Energy Storage Mater. 7 (2017) 130-151.

30 [6] C. P. Grey, J. M. Tarascon, Sustainability and in situ monitoring in battery development. Nat. Mater. 16 (2017) 45. 
[7] B. Chen, E. Liu, F. He, C. Shi, C. He, J. Li, N. Zhao, 2D sandwich-like carbon-coated ultrathin $\mathrm{TiO}_{2} @$ defect-rich $\mathrm{MoS}_{2}$ hybrid nanosheets: synergistic-effect-promoted electrochemical performance for lithium ion batteries. Nano Energy 26 (2016) 541-549.

[8] W. Huang, X. Xiao, C. Engelbrekt, M. Zhang, S. Li, J. Ulstrup, L. Ci, J. Feng, P. Si, Q. Chi, Graphene encapsulated $\mathrm{Fe}_{3} \mathrm{O}_{4}$ nanorods assembled into a mesoporous hybrid composite used as a highperformance lithium-ion battery anode material. Mater. Chem. Front. 1 (2017) 1185-1193.

[9] Y. Xiao, J.-Y. Hwang, I. Belharouak, Y.-K. Sun, Na storage capability investigation of a carbon nanotube-encapsulated $\mathrm{Fe}_{1-\mathrm{x}} \mathrm{S}$ composite. ACS Energy Lett. 2 (2017) 364-372.

[10] W. Huang, H. Sun, H. Shangguan, X. Cao, X. Xiao, F. Shen, K. Mølhave, L. Ci, P. Si, J. Zhang, Threedimensional iron sulfide-carbon interlocked graphene composites for high-performance sodium-ion storage. Nanoscale 10 (2018) 7851-7859.

[11] M.-R. Gao, Y.-F. Xu, J. Jiang, S.-H. Yu, Nanostructured metal chalcogenides: synthesis, modification, and applications in energy conversion and storage devices. Chem. Soc. Rev. 42 (2013) 2986-3017.

15 [12] W. Shi, J. Zhu, X. Rui, X. Cao, C. Chen, H. Zhang, H. H. Hng, Q. Yan, Controlled synthesis of carbon-coated cobalt sulfide nanostructures in oil phase with enhanced Li storage performances. ACS Appl. Mater. Interfaces 4 (2012) 2999-3006.

[13] H. Geng, J. Yang, Z. Dai, Y. Zhang, Y. Zheng, H. Yu, H. Wang, Z. Luo, Y. Guo, Y. Zhang, H. Fan, X. $\mathrm{Wu}$, J. Zheng, Y. Yang, Q. Yan, H. Gu, $\mathrm{Co}_{9} \mathrm{~S}_{8} / \mathrm{MoS}_{2}$ yolk-shell spheres for advanced Li/Na storage. Small 13 (2017) 1603490.

[14] Q. Zhou, L. Liu, Z. Huang, L. Yi, X. Wang, G. Cao, $\mathrm{Co}_{3} \mathrm{~S}_{4} @$ polyaniline nanotubes as highperformance anode materials for sodium ion batteries. J. Mater. Chem. A 4 (2016) 5505-5516.

[15] X. Liu, H. Liu, Y. Zhao, Y. Dong, Q. Fan, Q. Kuang, Synthesis of the carbon-coated nanoparticle $\mathrm{Co}_{9} \mathrm{~S}_{8}$ and its electrochemical performance as an anode material for sodium-ion batteries. Langmuir

$2532(2016)$ 12593-12602.

[16] X. Zhang, H. Wang, G. Wang, Cobalt sulfide nanoparticles anchored in three-dimensional carbon nanosheet networks for lithium and sodium ion batteries with enhanced electrochemical performance. J. Colloid Interface Sci. 492 (2017) 41-50.

[17] Z. Zhu, S. Wang, J. Du, Q. Jin, T. Zhang, F. Cheng, J. Chen, Ultrasmall Sn nanoparticles embedded

30 in nitrogen-doped porous carbon as high-performance anode for lithium-ion batteries. Nano Lett. 14 (2013) 153-157.

[18] C. Zhu, X. Mu, P. A. Van Aken, Y. Yu, J. Maier, Single-layered ultrasmall nanoplates of $\mathrm{MoS}_{2}$ embedded in carbon nanofibers with excellent electrochemical performance for lithium and sodium storage. Angew. Chem. Int. Ed. 126 (2014) 2184-2188.

35 [19] S. Zhang, D. Li, S. Chen, X. Yang, X. Zhao, Q. Zhao, S. Komarneni, D. Yang, Highly stable supercapacitors with MOF-derived $\mathrm{Co}_{9} \mathrm{~S}_{8} /$ carbon electrodes for high rate electrochemical energy storage. J. Mater. Chem. A 5 (2017) 12453-12461.

[20] H. Wang, S. Lu, Y. Chen, L. Han, J. Zhou, X. Wu, W. Qin, Graphene/Cog ${ }_{9} 8$ nanocomposite paper as a binder-free and free-standing anode for lithium-ion batteries. J. Mater. Chem. A 3 (2015) 2367723683.

[21] Z. Shadike, M.-H. Cao, F. Ding, L. Sang, Z.-W. Fu, Improved electrochemical performance of $\mathrm{CoS}_{2}-$ MWCNT nanocomposites for sodium-ion batteries. Chem. Commun. 51 (2015) 10486-10489.

[22] F. Zheng, Y. Yang, Q. Chen, High lithium anodic performance of highly nitrogen-doped porous carbon prepared from a metal-organic framework. Nat. Commun. 5 (2014) 5261.

45 [23] W. Shen, C. Wang, Q. Xu, H. Liu, Y. Wang, Nitrogen-doping-induced defects of a carbon coating layer facilitate Na-storage in electrode materials. Adv. Energy Mater. 5 (2015) 1400982.

[24] Y. Zhang, N. Wang, C. Sun, Z. Lu, P. Xue, B. Tang, Z. Bai, S. Dou, 3D spongy $\mathrm{CoS}_{2}$ nanoparticles/carbon composite as high-performance anode material for lithium/sodium ion batteries. Chem. Eng. J. 332 (2018) 370-376. 
[25] Y. Jiang, G. Zou, Hong, W.; Zhang, Y.; Zhang, Y.; Zhang, Y.; Shuai, H.; Xu, W.; Hou, H.; Ji, X. N-Rich carbon-coated $\mathrm{CO}_{3} \mathrm{~S}_{4}$ ultrafine nanocrystals derived from ZIF-67 as an advanced anode for SodiumIon Batteries. Nanoscale 10 (2018) 18786-18794.

[26] Z. Wang, L. Zhou, X. W. D. Lou, Metal oxide hollow nanostructures for lithium-ion batteries. Adv. Mater. 24 (2012) 1903-1911.

[27] K. Tang, L. Fu, R. J. White, L. Yu, M. M. Titirici, M. Antonietti, J. Maier, Hollow carbon nanospheres with superior rate capability for sodium-based batteries. Adv. Energy Mater. 2 (2012) 873-877.

[28] X. Y. Yu, L. Yu, X. W. D. Lou, Metal sulfide hollow nanostructures for electrochemical energy storage. Adv. Energy Mater. 6 (2016) 1501333.

[29] C. Dong, L. Guo, Y. He, L. Shang, Y. Q. Qian, L. Xu, Ultrafine $\mathrm{Co}_{1-\mathrm{X}} \mathrm{S}$ nanoparticles embedded in a nitrogen doped porous carbon hollow nanosphere composite as an anode for superb sodium-ion batteries and lithium-ion batteries. Nanoscale 10 (2018) 2804-2811.

[30] A. Indra, T. Song, U. Paik, Metal organic framework derived materials: progress and prospects for the energy conversion and storage. Adv. Mater. 30 (2018) 1705146.

[31] Y. Zhao, Z. Song, X. Li, Q. Sun, N. Cheng, S. Lawes, X. Sun, Metal organic frameworks for energy storage and conversion. Energy Storage Mater. 2 (2016) 35-62.

[32] C. Wang, Y. V. Kaneti, Y. Bando, J. Lin, C. Liu, J. Li, Y. Yamauchi, Metal-organic frameworkderived one-dimensional porous or hollow carbon-based nanofibers for energy storage and conversion. Mater. Horiz. 5 (2018) 394-407.

[33] X. -C. Xie, K. -J. Huang, X. Wu, Metal-organic framework derived hollow materials for electrochemical energy storage. J. Mater. Chem. A 6 (2018) 6754-6771.

[34] X. Ge, Z. Li, X. Rui, L. Yin, Metal-organic frameworks derived porous core/shellCoP@C polyhedrons anchored on 3D reduced graphene oxide networks as anode for sodium-ion battery. Nano Energy 32 (2017) 117-124.

[35] Y. Pan, K. Sun, S. Liu, X. Cao, K. Wu, W. -C. Cheong, Z. Chen, Y. Wang, Y. Li, Y. Liu, D. Wang, Q. Peng, C. Chen, Y. Li, Core-shell ZIF-8@ZIF-67-derived CoP nanoparticle-embedded N-doped carbon nanotube hollow polyhedron for efficient overall water splitting. J. Am. Chem. Soc. 140 (2018) 26102618.

30 [36] Y. Liang, J. Wei, Y. X. Hu, X. F. Chen, J. Zhang, X. Y. Zhang, S. P. Jiang, S. W. Tao, H. T. Wang, Metal-polydopamine frameworks and their transformation to hollow metal/N-doped carbon particles. Nanoscale 9 (2017) 5323-5328.

[37] J. Mujtaba, H. Sun, G. Huang, Y. Zhao, H. Arandiyan, G. Sun, S. Xun, J. Zhu, $\mathrm{Co}_{9} \mathrm{~S}_{8}$ nanoparticles encapsulated in nitrogen-doped mesoporous carbon networks with improved lithium storage 35 properties. RSC Adv. 6 (2016) 31775-31781.

[38] J. Liu, C. Wu, D. Xiao, P. Kopold, L. Gu, P. A. van Aken, J. Maier, Y. Yu, MOF-derived hollow $\mathrm{Co}_{9} \mathrm{~S}_{8}$ nanoparticles embedded in graphitic carbon nanocages with superior Li-ion storage. Small 12 (2016) 2354-2364.

[39] C. Avci, J. Ariñez-Soriano, A. Carné-Sánchez, V. Guillerm, C. Carbonell, I. Imaz, D. Maspoch, 40 Post-synthetic anisotropic wet-chemical etching of colloidal sodalite ZIF crystals. Angew. Chem. Int. Ed. 54 (2015) 14417-14421.

[40] H. Zhang, D. Liu, Y. Yao, B. Zhang, Y. Lin, Stability of ZIF-8 membranes and crystalline powders in water at room temperature. J. Membr. Sci. 485 (2015) 103-111.

[41] T. Zeng, H. Zhang, Z. He, J. Chen, S. Song, Mussel-inspired approach to constructing robust cobaltembedded $\mathrm{N}$-doped carbon nanosheet toward enhanced sulphate radical-based oxidation. Sci. Rep. 6 (2016) 33348.

[42] A. Bigotto, V. Galasso, G. De Alti, Infrared spectra and normal vibrations of cobalt (II), nickel (II) and palladium (II) complexes with N, N'-ethylenebis (acetylacetoneimine). Spectrochim. Acta Part A: Mol. Spectrosc. 28 (1972) 1581-1591. 
[43] J. Fu, Z. Chen, M. Wang, S. Liu, J. Zhang, J. Zhang, R. Han, Q. Xu, Adsorption of methylene blue by a high-efficiency adsorbent (polydopamine microspheres): kinetics, isotherm, thermodynamics and mechanism analysis. Chem. Eng. J. 259 (2015) 53-61.

[44] W. Huang, S. Li, X. Cao, C. Hou, Z. Zhang, J. Feng, L. Ci, P. Si, Q. Chi, Metal-organic framework derived iron sulfide-carbon core-shell nanorods as a conversion-type battery material. ACS Sustainable Chem. Eng. 5 (2017) 5039-5048.

[45] L.-L. Feng, M. Fan, Y. Wu, Y. Liu, G.-D. Li, H. Chen, W. Chen, D. Wang, X. Zou, Metallic $\mathrm{Co}_{9} \mathrm{~S}_{8}$ nanosheets grown on carbon cloth as efficient binder-free electrocatalysts for the hydrogen evolution reaction in neutral media. J. Mater. Chem. A 4 (2016) 6860-6867.

10 [46] G. Qu, H. Geng, D. Ge, M. Tang, J. Zheng, H. Gu, Porous carbon-wrapped mesoporous $\mathrm{Co}_{9} \mathrm{~S}_{8}$ fibers as stable anode for Li-ion batteries. Electrochim. Acta 211 (2016) 305-312.

[47] S. -J. Bao, Y. Li, C. M. Li, Q. Bao, Q. Lu, J. Guo, Shape evolution and magnetic properties of cobalt sulfide. Cryst. Growth Des. 8 (2008) 3745-3749.

[48] J. Pels, F. Kapteijn, J. Moulijn, Q. Zhu, K. Thomas, Evolution of nitrogen functionalities in carbonaceous materials during pyrolysis. Carbon 33 (1995) 1641-1653.

[49] K. Ai, Y. Liu, C. Ruan, L. Lu, G. M. Lu, Sp ${ }^{2}$ C-dominant N-doped carbon sub-micrometer spheres with a tunable size: a versatile platform for highly efficient oxygen-reduction catalysts. Adv. Mater. 25 (2013) 998-1003.

[50] X. Yang, J. Li, J. Liu, Y. Tian, B. Li, K. Cao, S. Liu, M. Hou, S. Li, L. Ma, Simple small molecule carbon source strategy for synthesis of functional hydrothermal carbon: preparation of highly efficient uranium selective solid phase extractant. J. Mater. Chem. A 2 (2014) 1550-1559.

[51] S. Dou, L. Tao, J. Huo, S. Wang, L. Dai, Etched and doped $\mathrm{Co}_{9} \mathrm{~S}_{8} /$ graphene hybrid for oxygen electrocatalysis. Energy Environ. Sci., 9 (2016) 1320-1326.

[52] X. Wang, S. -X. Zhao, L. Dong, Q. -L. Lu, J. Zhu, C. -W. Nan. One-step synthesis of surfaceenriched nickel cobalt sulfide nanoparticleson graphene for high-performance supercapacitors. Energy Storage Mater. 6 (2017) 180-187.

[53] L.-L. Feng, G.-D. Li, Y. Liu, Y. Wu, H. Chen, Y. Wang, Y.-C. Zou, D. Wang, X. Zou, Carbon-armored $\mathrm{Co}_{9} \mathrm{~S}_{8}$ nanoparticles as all-pH efficient and durable $\mathrm{H}_{2}$-evolving electrocatalysts. ACS Appl. Mater. Interfaces 7 (2015) 980-988.

30 [54] R. Jin, J. Zhou, Y. Guan, H. Liu, G. Chen, Mesocrystal $\mathrm{Co}_{9} \mathrm{~S}_{8}$ hollow sphere anodes for high performance lithium ion batteries. J. Mater. Chem. A 2 (2014) 13241-13244.

[55] N. Liu, Z. Lu, J. Zhao, M. T. McDowell, H. -W. Lee, W. Zhao, Y. Cui, A pomegranate-inspired nanoscale design for large-volume-change lithium battery anodes. Nat. Nanotechnol. 9 (2014) 187192.

35 [56] Z. Zhang, Y. Gan, Y. Lai, X. Shi, W. Chen, J. Li, Cobalt sulfides/dodecahedral porous carbon as anode materials for Na-ion batteries. RSC Adv. 5 (2015) 103410-103413.

[57] Y. Zhu, Y. Wen, X. Fan, T. Gao, F. Han, C. Luo, S.-C. Liou, C. Wang, Red phosphorus-single-walled carbon nanotube composite as a superior anode for sodium ion batteries ACS Nano 9 (2015) 32543264.

40 [58] E. Peled, S. Menkin, SEI: past, present and future. J. Electrochem. Soc. 164 (2017) A1703-A1719. [59] A. Wang, S. Kadam, H. Li, S. Shi, Y. Qi, Review on modeling of the anode solid electrolyte interphase (SEI) for lithium-ion batteries. npj Comput. Mater. 4(2018) 15. 
Well-Defined Cobalt Sulfide Nanoparticles Locked in 3D Hollow

5 Nitrogen-Doped Carbon Shells for Superior Lithium and Sodium Storage

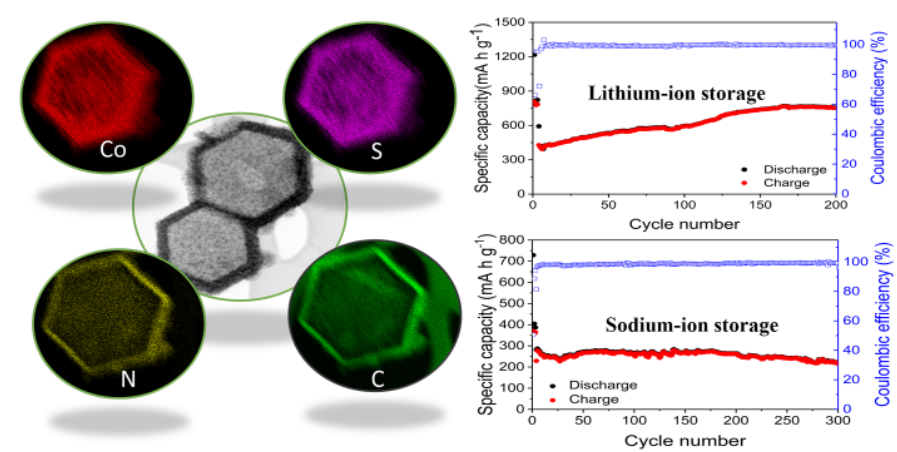




\section{Supporting Information}

\section{Well-Defined Cobalt Sulfide Nanoparticles Locked in 3D Hollow Nitrogen-Doped Carbon Shells for Superior Lithium and Sodium Storage}

Huihui Shangguan, a, 1 Wei Huang, b, 1 Christian Engelbrekt, b, c Xiaowen Zheng, ${ }^{a}$ Fei Shen, ${ }^{b}$ Xinxin Xiao, ${ }^{\text {b, d }}$ Lijie Ci, ${ }^{a}$ Pengchao $\mathrm{Si}^{\text {a }}{ }^{*}$ and Jingdong Zhang ${ }^{\text {b, * }}$

${ }^{a}$ SDU \& Rice Joint Center for Carbon Nanomaterials, Key Laboratory for Liquid-Solid Structural Evolution and Processing of Materials, Ministry of Education, School of Materials Science and Engineering, Shandong University, Jinan 250061, P. R. China.

${ }^{b}$ Department of Chemistry, Technical University of Denmark, DK-2800 Kongens Lyngby, Denmark.

${ }^{c}$ Department of Chemistry, University of California Irvine, Irvine, California, 92697, United States.

${ }^{d}$ Department of Chemical Sciences and Bernal Institute, University of Limerick, Limerick, Ireland. 


\section{Supplementary figures and table}
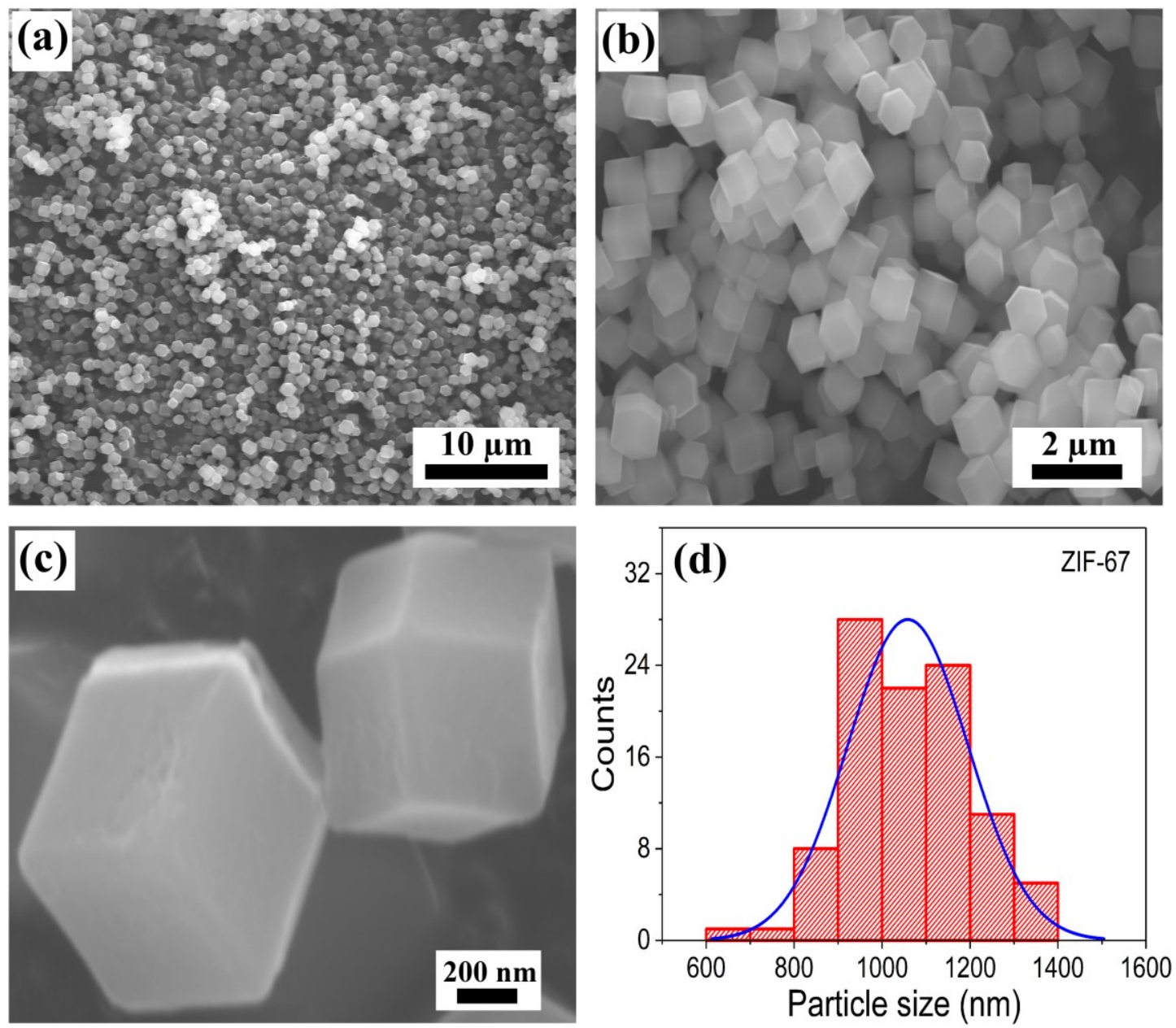

Fig. S1. (a, b, c) SEM images of ZIF-67 crystals. (d) The particle size distribution of ZIF-67 crystals corresponding to Fig. S1a.
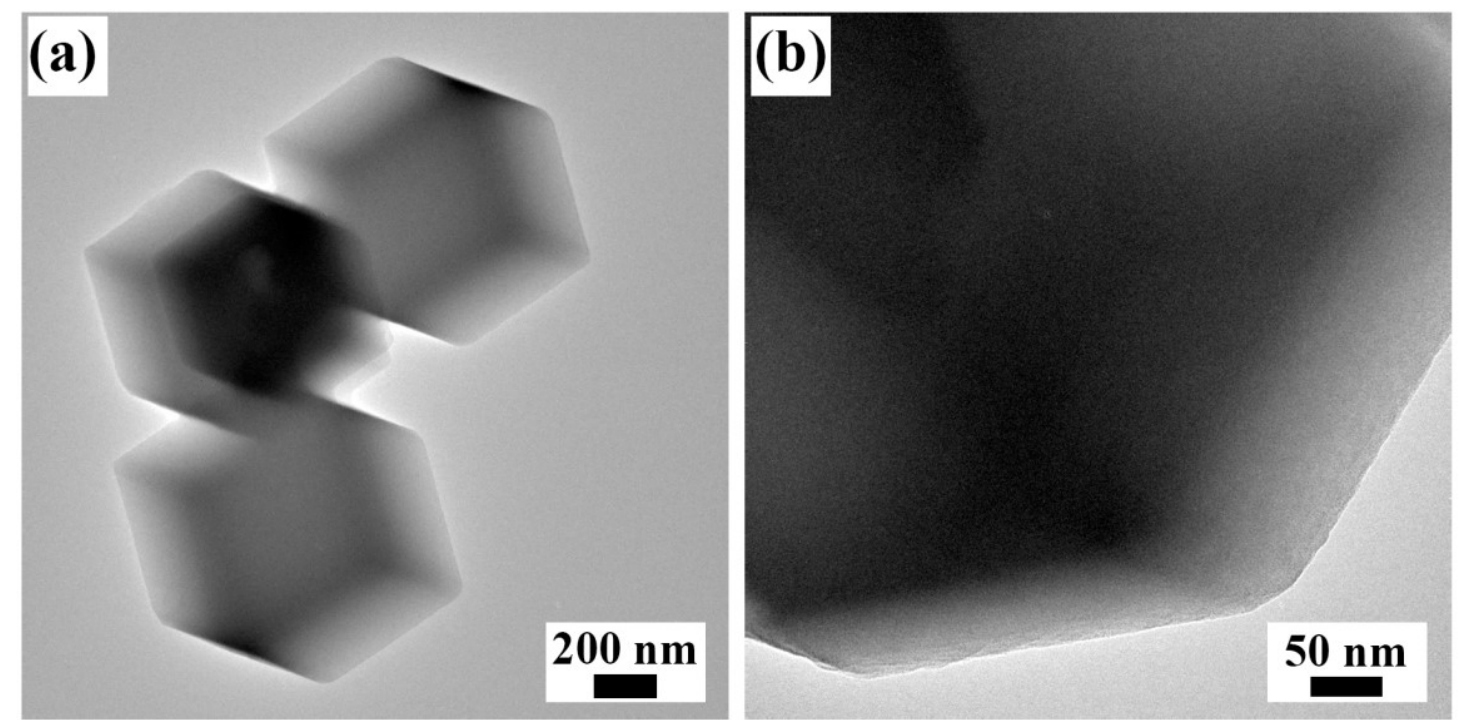

Fig.S2. (a, b) TEM images of ZIF-67 crystals. 

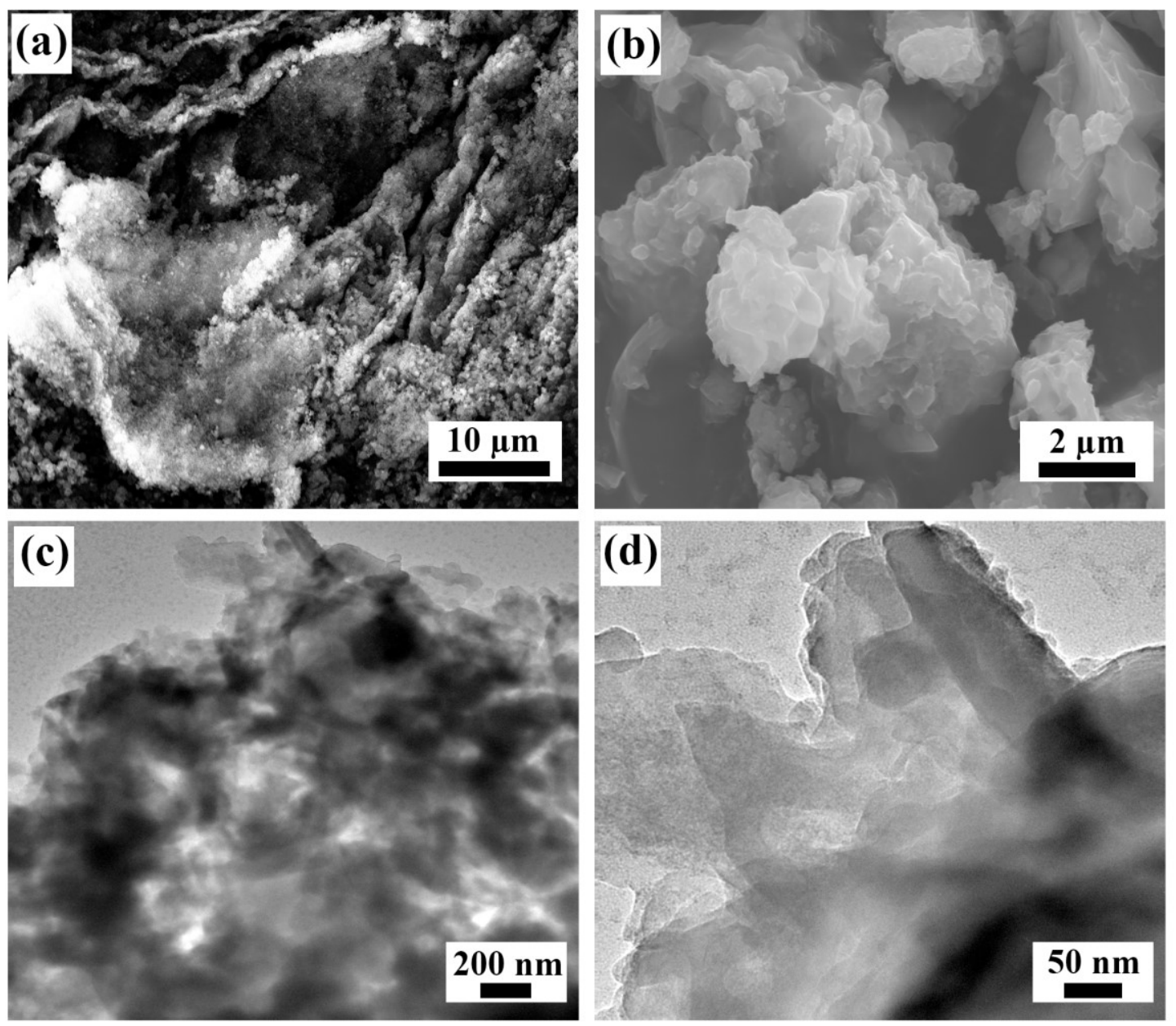

Fig. S3. SEM (a, b) and TEM (c, d) images of the PDA@ZIF-67 composite prepared with $0.5 \mathrm{mg}$ $\mathrm{mL}^{-1} \mathrm{DAH}$. 

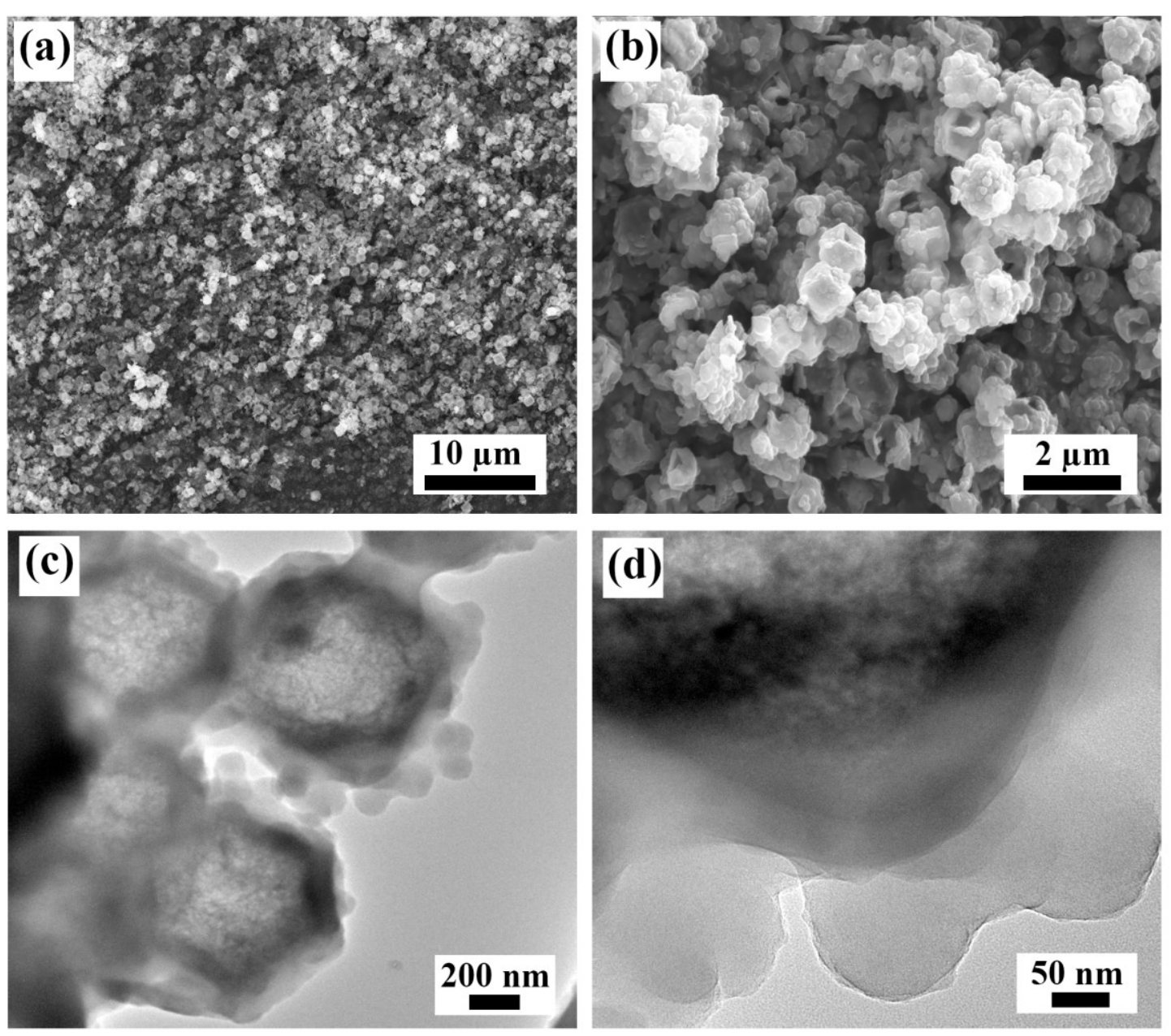

Fig. S4. SEM (a, b) and TEM (c, d) images of the PDA@ZIF-67 composite prepared with $2.0 \mathrm{mg}$ $\mathrm{mL}^{-1} \mathrm{DAH}$. 

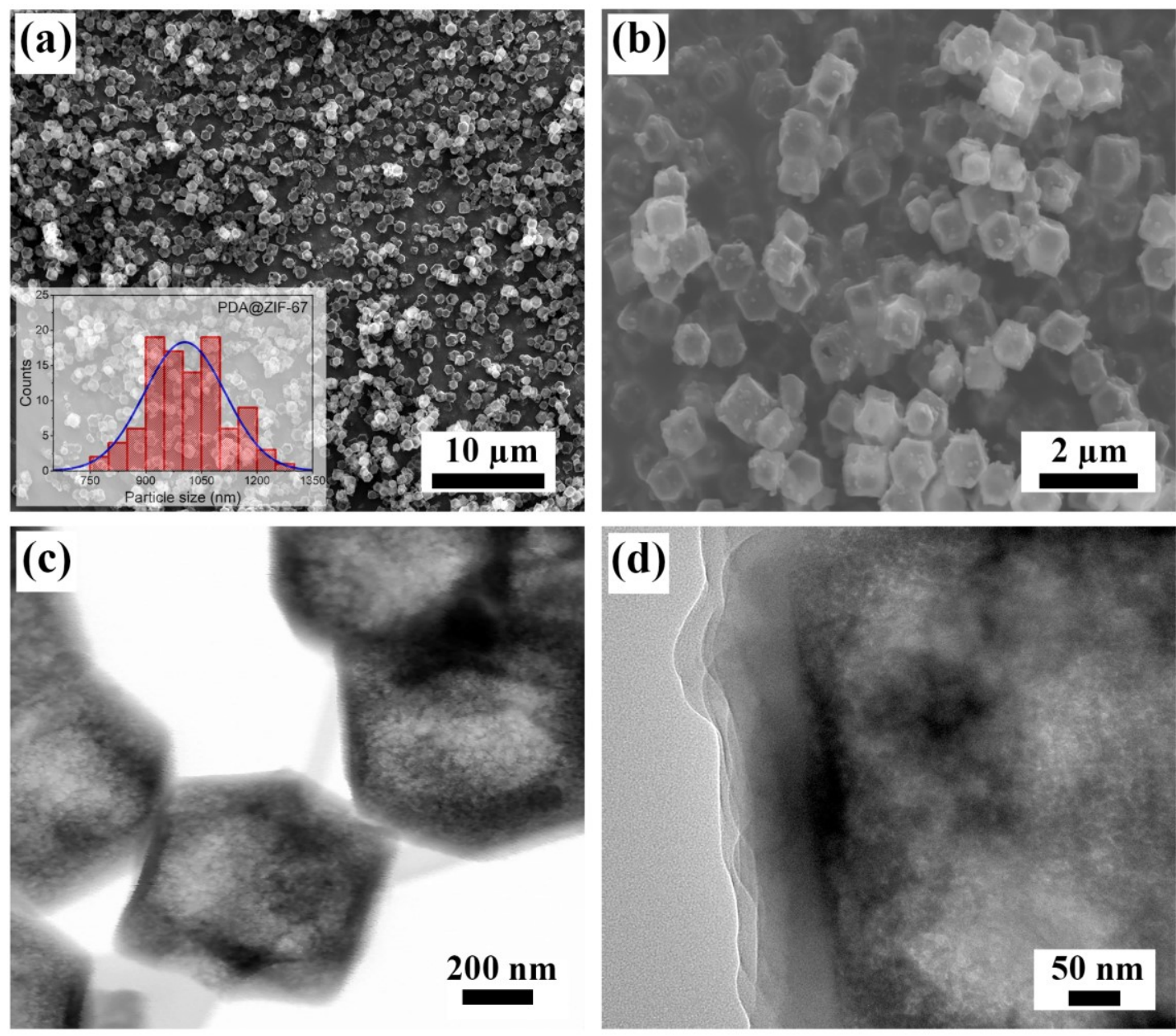

Fig. S5. SEM (a, b) and TEM (c, d) images of PDA@ZIF-67 composite prepared with $1.0 \mathrm{mg} \mathrm{mL}^{-1}$ dopamine hydrochloride. Insert is the particle size distribution of PDA@ZIF-67 composite corresponding to Fig. S5a. 

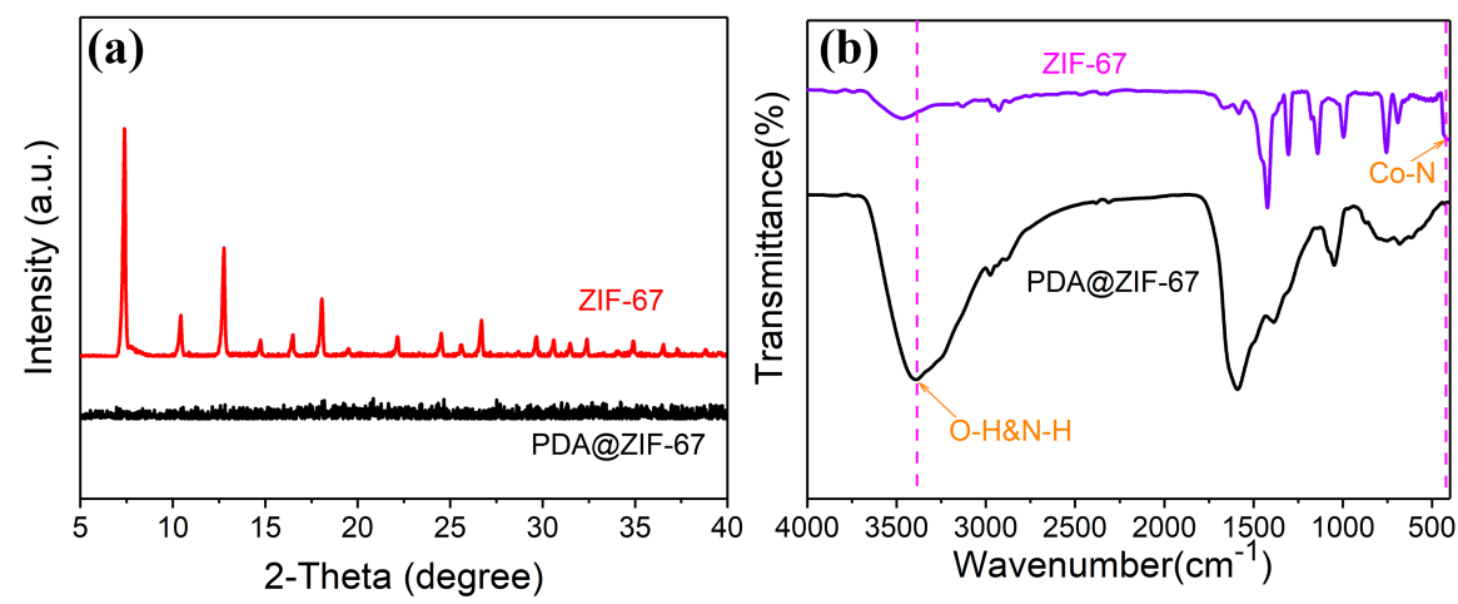

Fig. S6. (a) The XRD pattern of ZIF-67 crystals and PDA@ZIF-67 composite (1.0 mg mL $\mathrm{m}^{-1}$ dopamine hydrochloride). (b) FT-IR spectrum of the ZIF-67 crystals and PDA@ZIF-67 composites (1.0 mg $\mathrm{mL}^{-1}$ dopamine hydrochloride).

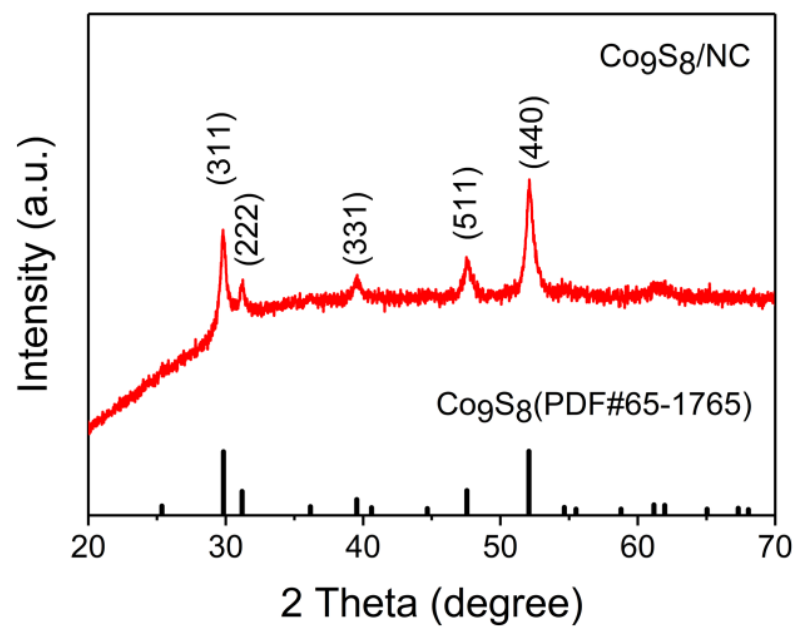

Fig. S7. The XRD pattern of $\mathrm{Co}_{9} \mathrm{~S}_{8} / \mathrm{NC}$ composite. 


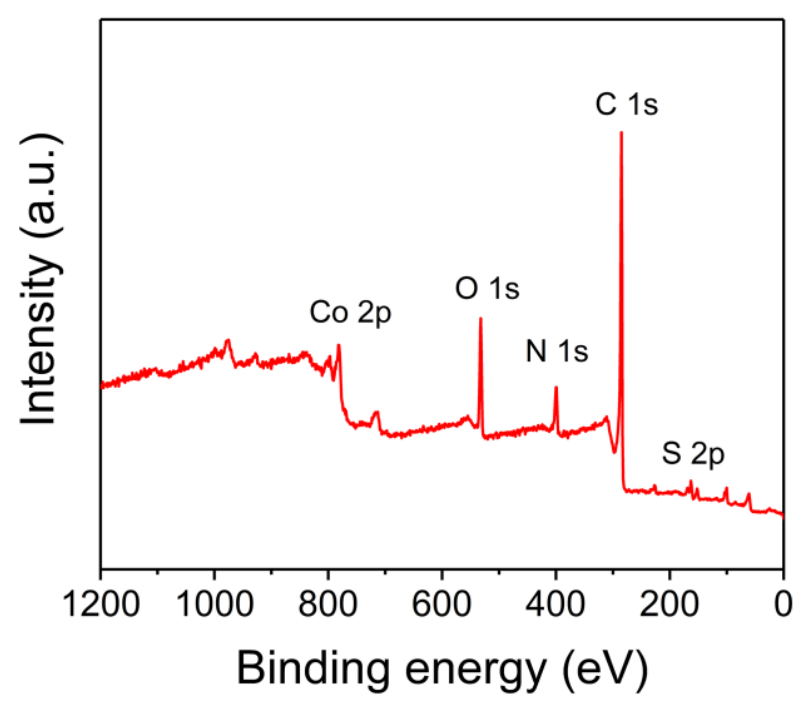

Fig. S8. The XPS survey spectrum of $\mathrm{Co}_{9} \mathrm{~S}_{8} / \mathrm{HNCS}$ composite.

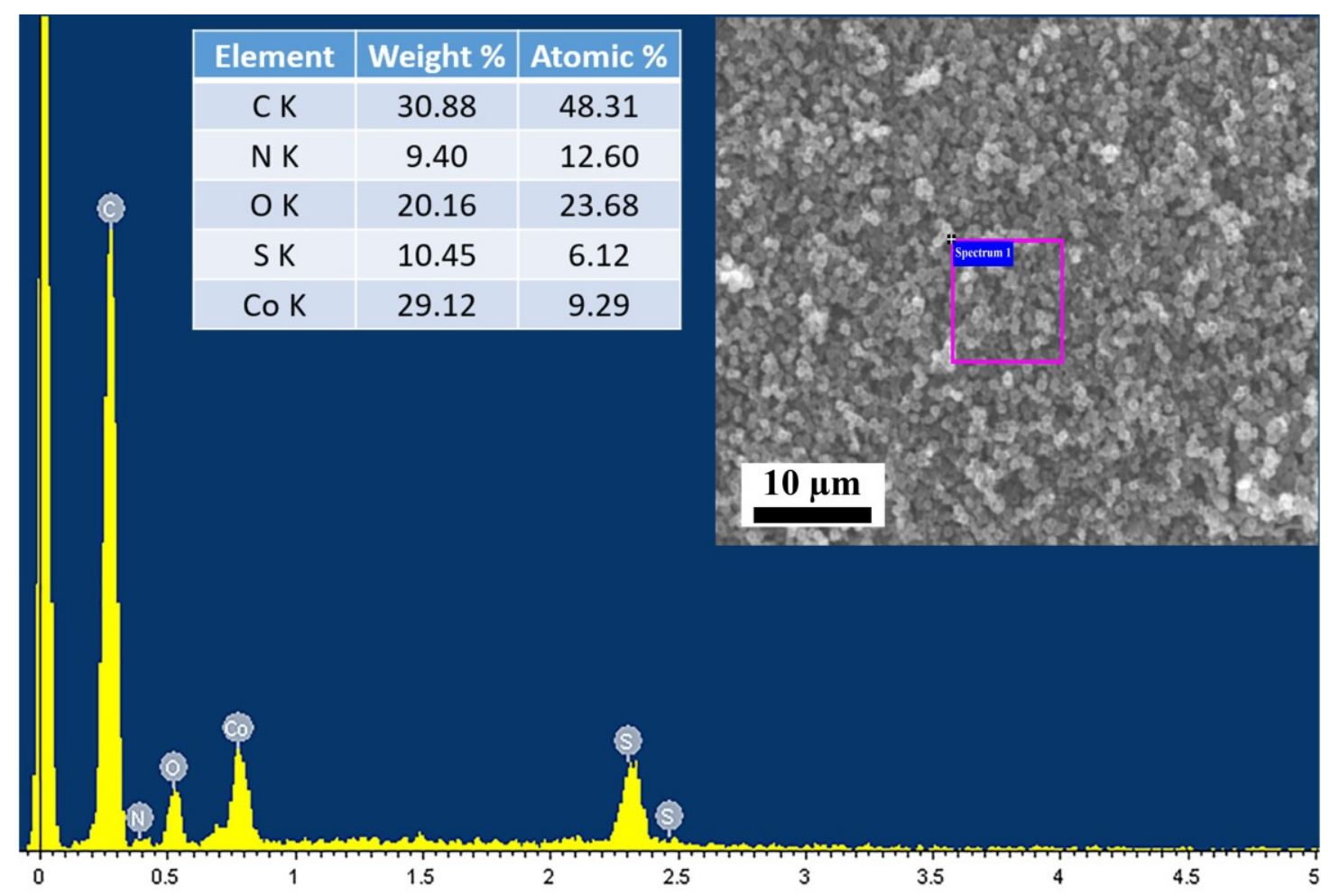

Fig. S9. EDS mapping image of the $\mathrm{Co}_{9} \mathrm{~S}_{8} / \mathrm{HNCS}$ composite. Inset is SEM image of the scanning area of the $\mathrm{Co}_{9} \mathrm{~S}_{8} / \mathrm{HNCS}$ composite. 

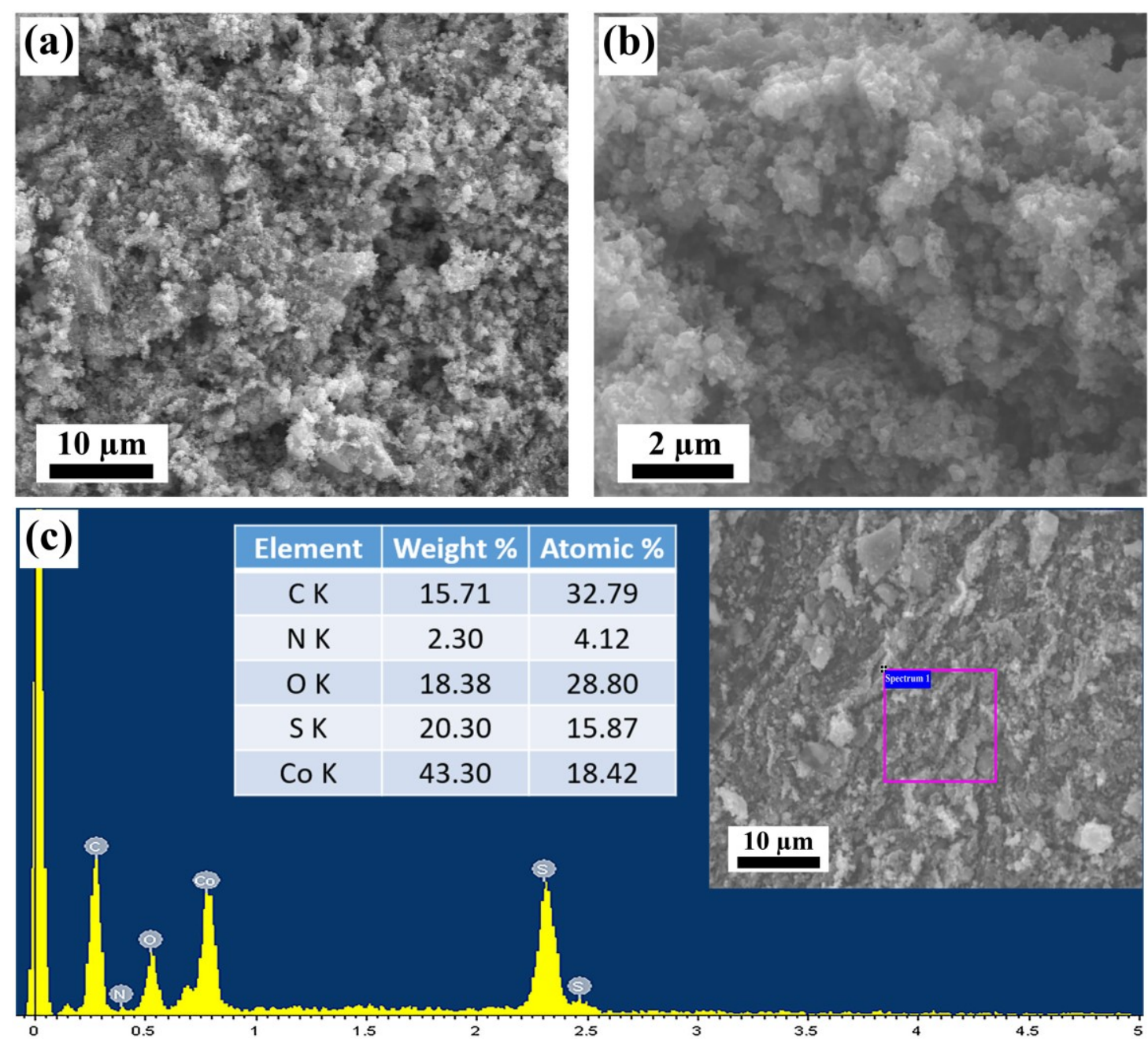

Fig. S10. (a, b) SEM images of $\mathrm{Co}_{9} \mathrm{~S}_{8} / \mathrm{NC}$ composite. (c) EDS mapping image of the $\mathrm{Co}_{9} \mathrm{~S}_{8} / \mathrm{NC}$ composite. Inset is the scanning area.
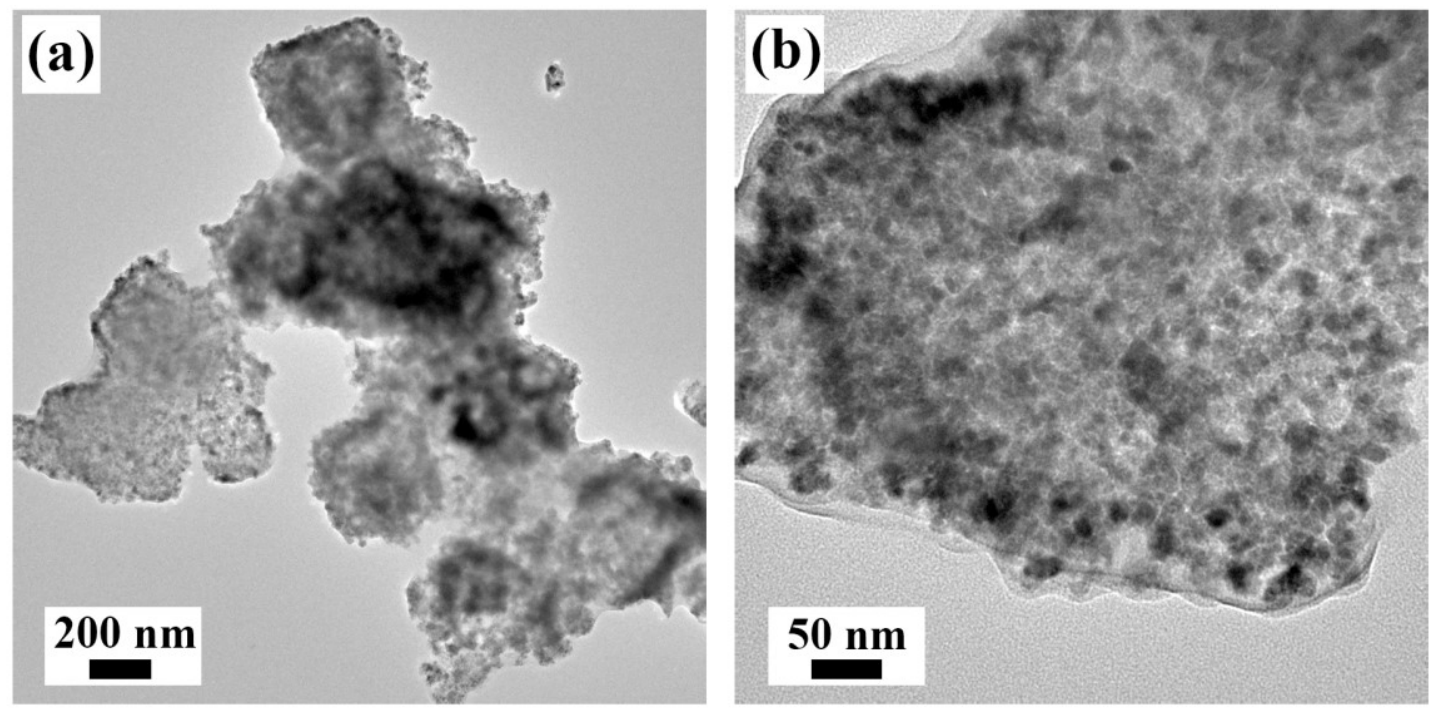

Fig. S11. (a, b) TEM images of $\mathrm{Co}_{9} \mathrm{~S}_{8} / \mathrm{NC}$ composite. 

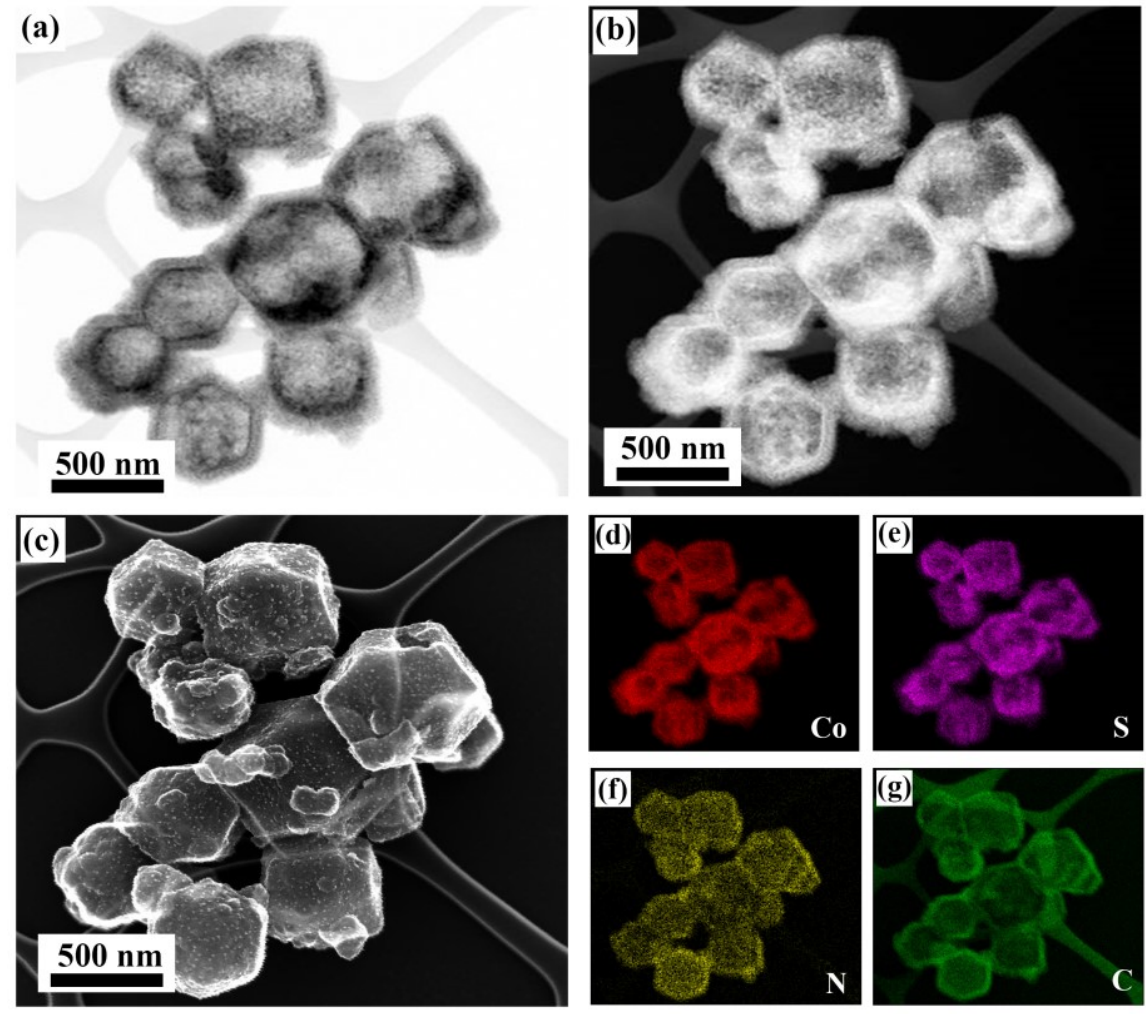

Fig. S12. (a) Bright-field, (b) dark-field, (c) secondary electron images and (d-g) EDS elemental map of large-scale $\mathrm{Co}_{9} \mathrm{~S}_{8} /$ HNCS composite for TEM test. 

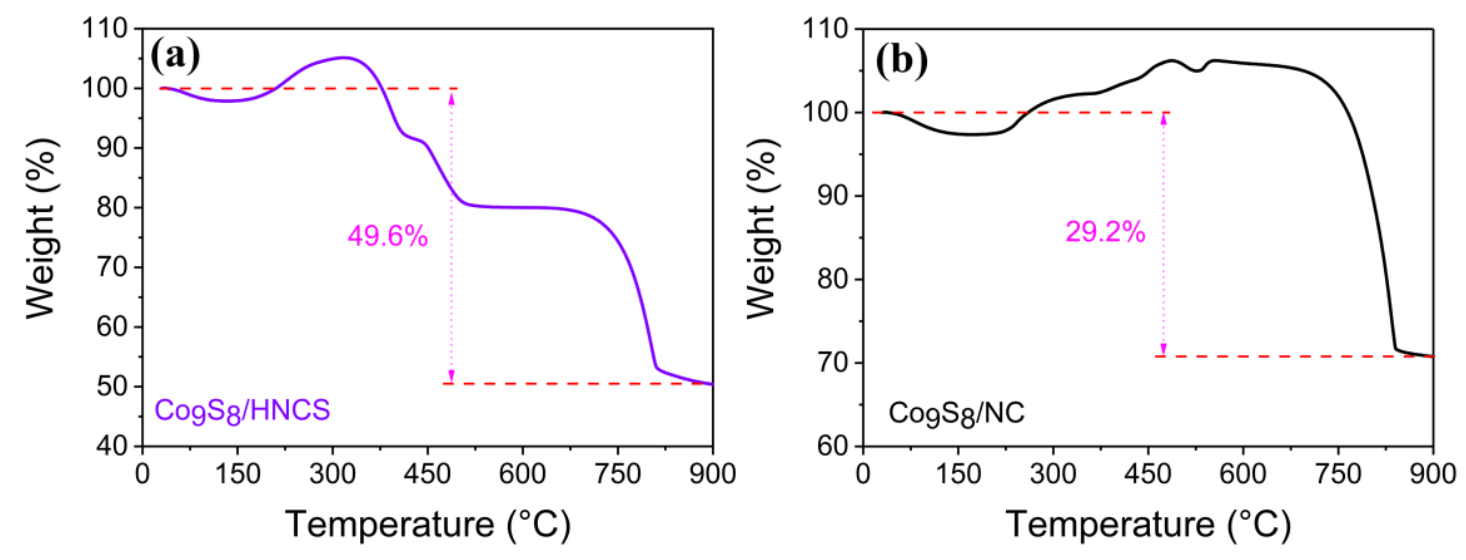

Fig. S13. (a, b) TGA curves of the $\mathrm{Co}_{9} \mathrm{~S}_{8} / \mathrm{HNCS}(\mathrm{a})$ and $\mathrm{Co}_{9} \mathrm{~S}_{8} / \mathrm{NC}(\mathrm{b})$ composites.

The component calculation of $\mathrm{Co}_{9} \mathrm{~S}_{8} / \mathrm{HNCS}$ composite:

$1 \mathrm{Co}_{9} \mathrm{~S}_{8} / \mathrm{HNCS} \sim 3 \mathrm{Co}_{3} \mathrm{O}_{4} \quad$ (TGA chemical transformation)

$1 \mathrm{~mol}\left(\mathrm{Co}_{9} \mathrm{~S}_{8}\right) \sim 3 \mathrm{~mol}\left(\mathrm{Co}_{3} \mathrm{O}_{4}\right) \quad$ (relative molecular mass)

$1 \times 787 \sim 3 \times 241 \quad$ (mass conservation)

$\mathrm{Y} \quad \sim \quad 50.4 \%$

Calculated the percentage of cobalt sulfide $\left(\mathrm{Co}_{9} \mathrm{~S}_{8}\right) \mathrm{Y}=50.4 \% \times 1 \times 787 /(3 \times 241)=54.9 \%$.

The component calculation of $\mathrm{Co}_{9} \mathrm{~S}_{8} / \mathrm{NC}$ composite:

$1 \mathrm{Co}_{9} \mathrm{~S}_{8} / \mathrm{NC} \sim 3 \mathrm{Co}_{3} \mathrm{O}_{4} \quad$ (TGA chemical transformation)

$1 \mathrm{~mol}\left(\mathrm{Co}_{9} \mathrm{~S}_{8}\right) \sim 3 \mathrm{~mol}\left(\mathrm{Co}_{3} \mathrm{O}_{4}\right) \quad$ (relative molecular mass)

$1 \times 787 \sim 3 \times 166 \quad$ (mass conservation)

$\mathrm{Y} \sim 70.8 \%$

Calculated the percentage of cobalt sulfide $\left(\mathrm{Co}_{9} \mathrm{~S}_{8}\right) \mathrm{Y}=70.8 \% \times 1 \times 787 /(3 \times 241)=77.1 \%$. 

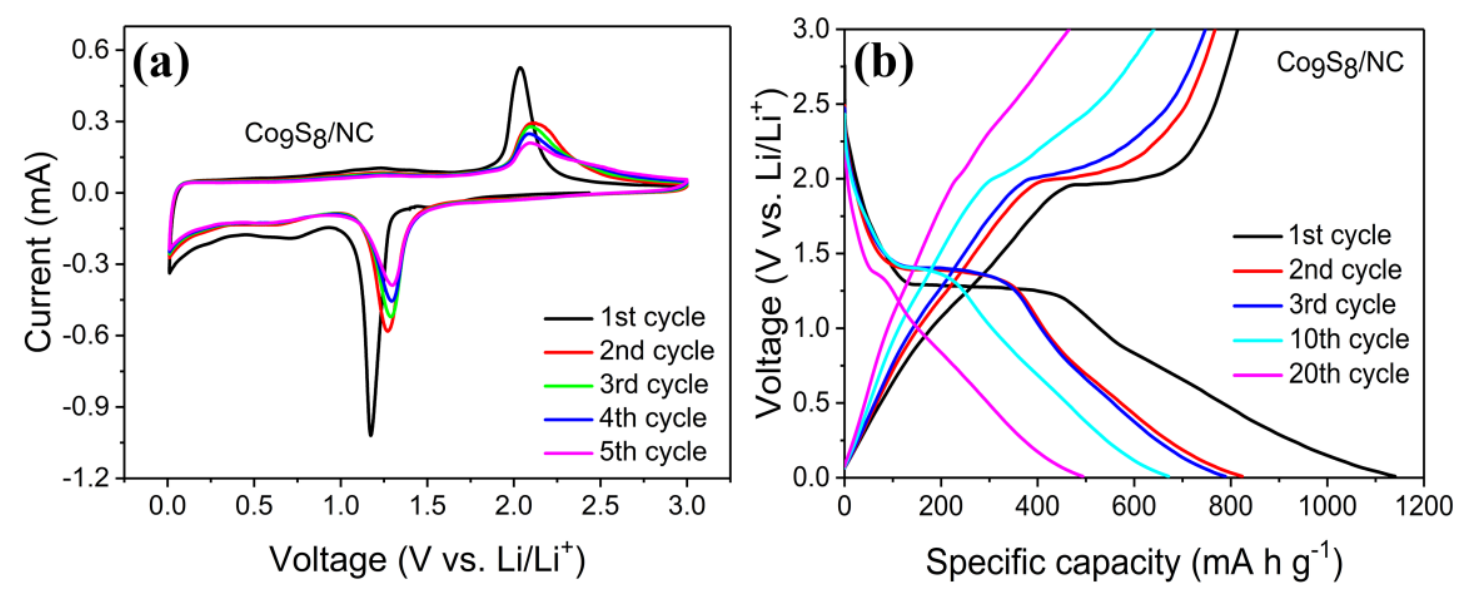

Fig. S14. (a) Cyclic voltammograms of the first five cycles of $\mathrm{Co}_{9} \mathrm{~S}_{8} / \mathrm{NC}$ composite in a voltage range of $0.01-3.0 \mathrm{~V}$ with a scanning rate of $0.1 \mathrm{mV} \mathrm{s}^{-1}$. (b) Galvanostatic discharge/charge profiles of the first three, $10^{\text {th }}$ and $20^{\text {th }}$ cycles of $\mathrm{Co}_{9} \mathrm{~S}_{8} / \mathrm{NC}$ composite at a current density of $100 \mathrm{~mA} \mathrm{~g}^{-1}$.

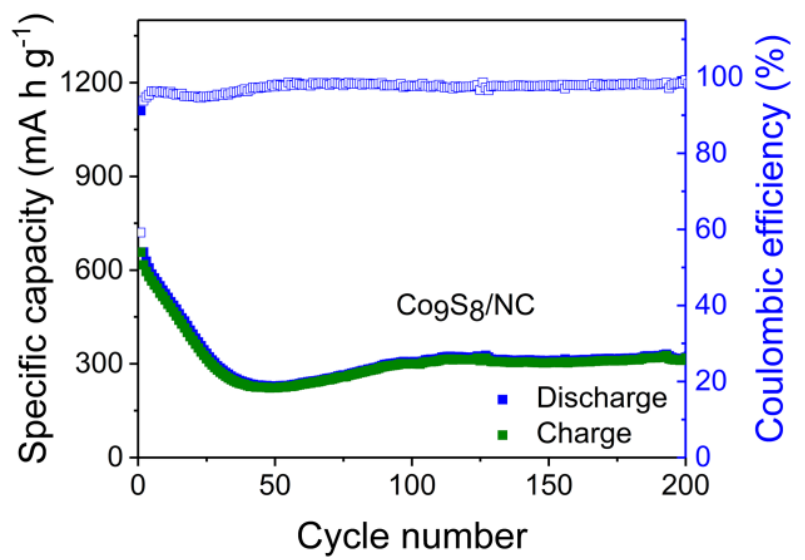

Fig. S15. The long-term cycle performance of $\mathrm{Co}_{9} \mathrm{~S}_{8} / \mathrm{NC}$ composite at a current rate of $500 \mathrm{~mA} \mathrm{~g}^{-1}$. 
Table S1. Comparison of electrochemical performances of $\mathrm{Co}_{9} \mathrm{~S}_{8} / \mathrm{HNCS}$ composite with previously reported cobalt sulfides related systems for lithium storage.

\begin{tabular}{|c|c|c|c|c|}
\hline Composites & $\begin{array}{l}\text { Current } \\
\left(\mathrm{mA}^{-1}\right)\end{array}$ & $\begin{array}{c}\text { Cycle } \\
\text { number }\end{array}$ & $\begin{array}{l}\text { Capability } \\
\left(\mathrm{mAh} \mathrm{g}^{-1}\right)\end{array}$ & Ref. \\
\hline $\mathrm{Co}_{9} \mathrm{~S}_{8}$ hollow sphere & 100 & 100 & 254.9 & [1] \\
\hline $\begin{array}{c}\mathrm{CoS}_{2} \text { nanobubble } \\
\text { hollow prisms }\end{array}$ & 1000 & 200 & 737 & [2] \\
\hline $\mathrm{Cog}_{8} / \mathrm{MoS}_{2}$ & 1000 & 70 & 756 & [3] \\
\hline $\mathrm{Co}_{1-\mathrm{x}} \mathrm{S} / \mathrm{BC}$ & 100 & 120 & 630 & [4] \\
\hline $\mathrm{C} @ \mathrm{Cog}_{8}$ & 1000 & 50 & 520 & {$[5]$} \\
\hline $\mathrm{Co}_{9} \mathrm{~S}_{8} / \mathrm{C}$ & 200 & 150 & 709 & [6] \\
\hline $\mathrm{Cog}_{9} \mathrm{~S}_{8} @ \mathrm{C}$ & 539 & 300 & 606 & [7] \\
\hline $\mathrm{Co}_{3} \mathrm{~S}_{4} / \mathrm{MWCNT}$ & 2000 & 500 & 976.5 & [8] \\
\hline $\mathrm{Co}_{9} \mathrm{~S}_{8}-\mathrm{GNS}$ & 500 & 100 & 414 & [9] \\
\hline $\mathrm{RGO} / \mathrm{Co}_{9} \mathrm{~S}_{8}$ & 545 & 500 & 382.2 & {$[10]$} \\
\hline $\mathrm{C} \&$ graphene $\mathrm{Co}_{9} \mathrm{~S}_{8}$ & 200 & 50 & 609 & {$[11]$} \\
\hline $\mathrm{Cog}_{9} \mathrm{~S}_{8} @ N M C N$ & 100 & 80 & 988 & {$[12]$} \\
\hline CogS $@ @ C$ nanocages & 544 & 30 & 54 & [13] \\
\hline $\mathrm{Co}_{9} \mathrm{~S}_{8} / \mathrm{NC}$ & 500 & 200 & 321 & This work \\
\hline $\mathrm{CO}_{9} \mathrm{~S}_{8} / \mathrm{HNCS}$ & 500 & 200 & 755 & This work \\
\hline
\end{tabular}





Fig. S16. (a) Cyclic voltammograms of the first five cycles of $\mathrm{Co}_{9} \mathrm{~S}_{8} / \mathrm{NC}$ composite in a voltage range of $0.01-3.0 \mathrm{~V}$ with a scanning rate of $0.1 \mathrm{mV} \mathrm{s}^{-1}$. (b) Galvanostatic discharge/charge profiles of the first three, $10^{\text {th }}$ and $20^{\text {th }}$ cycles of $\mathrm{Co}_{9} \mathrm{~S}_{8} / \mathrm{NC}$ composite at a current density of $100 \mathrm{~mA} \mathrm{~g}^{-1}$.

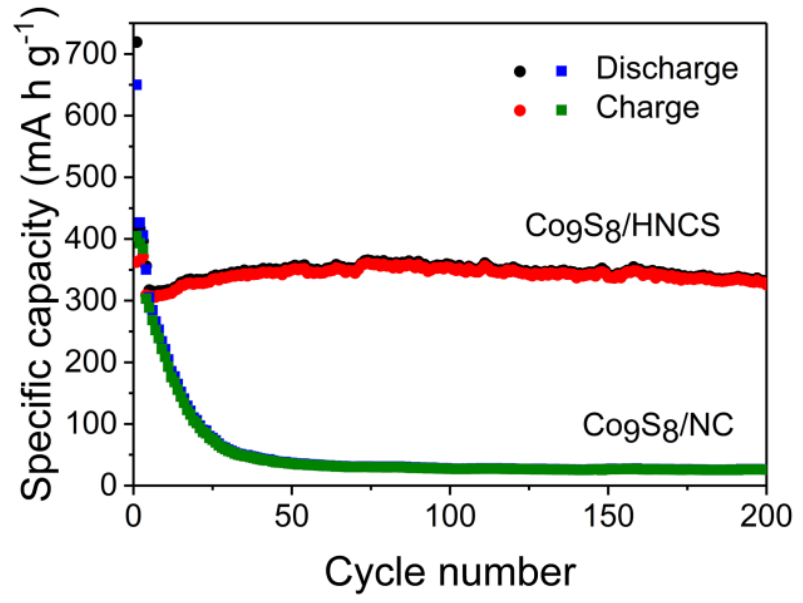

Fig. S17. The long-term cycle performance of $\mathrm{Co}_{9} \mathrm{~S}_{8} / \mathrm{HNCS}$ and $\mathrm{Co}_{9} \mathrm{~S}_{8} / \mathrm{NC}$ composites at a current density of $500 \mathrm{~mA} \mathrm{~g}^{-1}$.



Fig. S18. The long-term cycle performance of $\mathrm{Co}_{9} \mathrm{~S}_{8} / \mathrm{NC}$ composite at a current density of 1000 $\mathrm{mA} \mathrm{g}{ }^{-1}$. 
Table S2. Comparison of electrochemical performances of $\mathrm{C}_{9} \mathrm{~S}_{8} / \mathrm{HNCS}$ composite with previously reported cobalt sulfides related systems for sodium storage.

\begin{tabular}{|c|c|c|c|c|}
\hline Composites & $\begin{array}{l}\text { Current } \\
\left(\mathrm{mAg}^{-1}\right)\end{array}$ & $\begin{array}{c}\text { Cycle } \\
\text { number }\end{array}$ & $\begin{array}{l}\text { Capability } \\
\left(\text { mAh g }^{-1}\right)\end{array}$ & Ref. \\
\hline $\mathrm{CO}_{1-\mathrm{x}} \mathrm{S} / \mathrm{C}$ & 1000 & 130 & 320 & {$[14]$} \\
\hline $\mathrm{CoS} / \mathrm{rGO}$ & 100 & 100 & 230 & [15] \\
\hline $\mathrm{CoS}_{2}-\mathrm{MWCNT}$ & 100 & 100 & 568 & {$[16]$} \\
\hline $\mathrm{Co}_{3} \mathrm{~S}_{4} @ P A N I$ & 200 & 100 & 252.5 & [17] \\
\hline $\mathrm{CS}-\mathrm{CO}_{\mathrm{x}} \mathrm{S}_{\mathrm{y}} / \mathrm{DPC}$ & 500 & 50 & 300 & {$[18]$} \\
\hline $\mathrm{Cog}_{8} \mathrm{~S}_{8}$-carbon & 500 & 50 & 404 & [19] \\
\hline $\mathrm{Co}_{9} \mathrm{~S}_{8} / \mathrm{C}$ & 5 & 30 & 320 & [20] \\
\hline CogS8@C nanospheres & 500 & 100 & 405 & {$[21]$} \\
\hline $\mathrm{Cog}_{9} \mathrm{~S}_{8} @ \mathrm{CNNs}$ & 100 & 50 & 249 & {$[22]$} \\
\hline $\mathrm{Co}_{9} \mathrm{~S}_{8} / \mathrm{NC}$ & 500 & 200 & 26 & This work \\
\hline $\mathrm{Co}_{9} \mathrm{~S}_{8} / \mathrm{NC}$ & 1000 & 300 & 19 & This work \\
\hline $\mathrm{CO}_{9} \mathrm{~S}_{8} / \mathrm{HNCS}$ & 500 & 200 & 327 & This work \\
\hline $\mathrm{CO}_{9} \mathrm{~S}_{8} / \mathrm{HNCS}$ & 1000 & 300 & 224 & This work \\
\hline
\end{tabular}



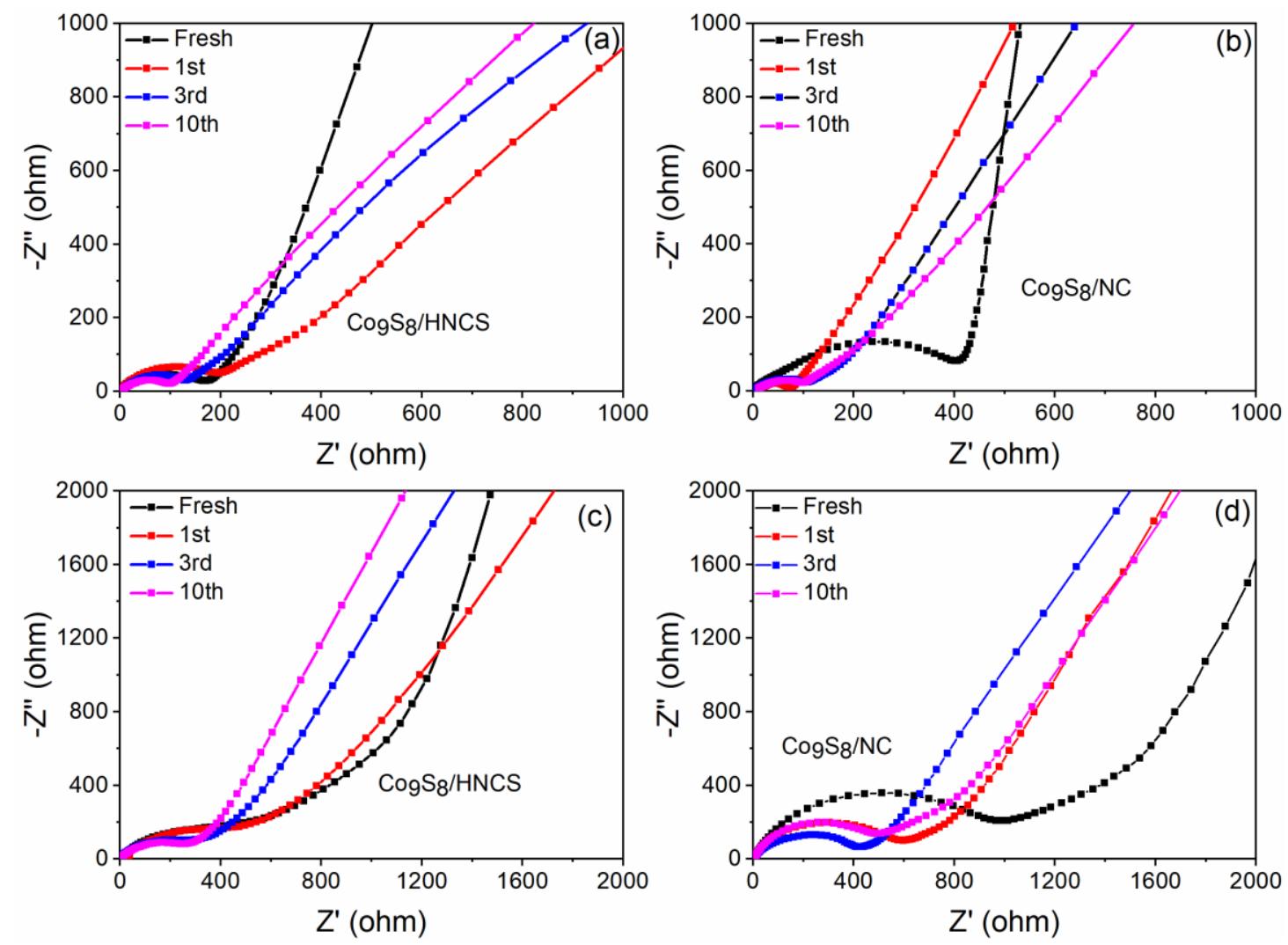

Fig. S19. (a, b) Nyquist impedance plots of $\mathrm{Co}_{9} \mathrm{~S}_{8} / \mathrm{HNCS}$ and $\mathrm{Co}_{9} \mathrm{~S}_{8} / \mathrm{NC}$ composites as lithium-ion storage materials before the $1^{\text {st }}$ cycle and after the $1^{\text {st }}, 3^{\text {rd }}$ and $10^{\text {th }}$ cycles. (c, d) Nyquist impedance plots of $\mathrm{Co}_{9} \mathrm{~S}_{8} / \mathrm{HNCS}$ and $\mathrm{Co}_{9} \mathrm{~S}_{8} / \mathrm{NC}$ composites as sodium-ion storage materials before the $1^{\text {st }}$ cycle and after the $1^{\text {st }}, 3^{\text {rd }}$ and $10^{\text {th }}$ cycles.

Table S3. The corresponded $\mathrm{R}_{\mathrm{ct}}$ values of $\mathrm{CO}_{9} \mathrm{~S}_{8} / \mathrm{HNCS}$ and $\mathrm{Co}_{9} \mathrm{~S}_{8} / \mathrm{NC}$ in different cycles for lithium and sodium ion storage.

\begin{tabular}{ccccc}
\hline & \multicolumn{2}{c}{$\mathbf{R}_{\mathrm{ct}}$ of Lithium ion storage $(\boldsymbol{\Omega})$} & \multicolumn{2}{c}{$\mathbf{R}_{\mathrm{ct}}$ of Sodium ion storage $(\boldsymbol{\Omega})$} \\
\cline { 2 - 5 } & $\mathrm{Co}_{9} \mathbf{S}_{8} /$ HNCS & $\mathrm{Co}_{9} \mathbf{S}_{8} / \mathbf{N C}$ & $\mathbf{C o}_{9} \mathbf{S}_{8} /$ HNCS & Co $_{9} \mathbf{S}_{8} / \mathbf{N C}$ \\
\hline Fresh & 172 & 400 & 447 & 915 \\
\hline $1^{\text {st }}$ & 179 & 71 & 445 & 566 \\
\hline $3^{\text {rd }}$ & 121 & 103 & 283 & 409 \\
\hline $10^{\text {th }}$ & 94 & 97 & 270 & 459
\end{tabular}



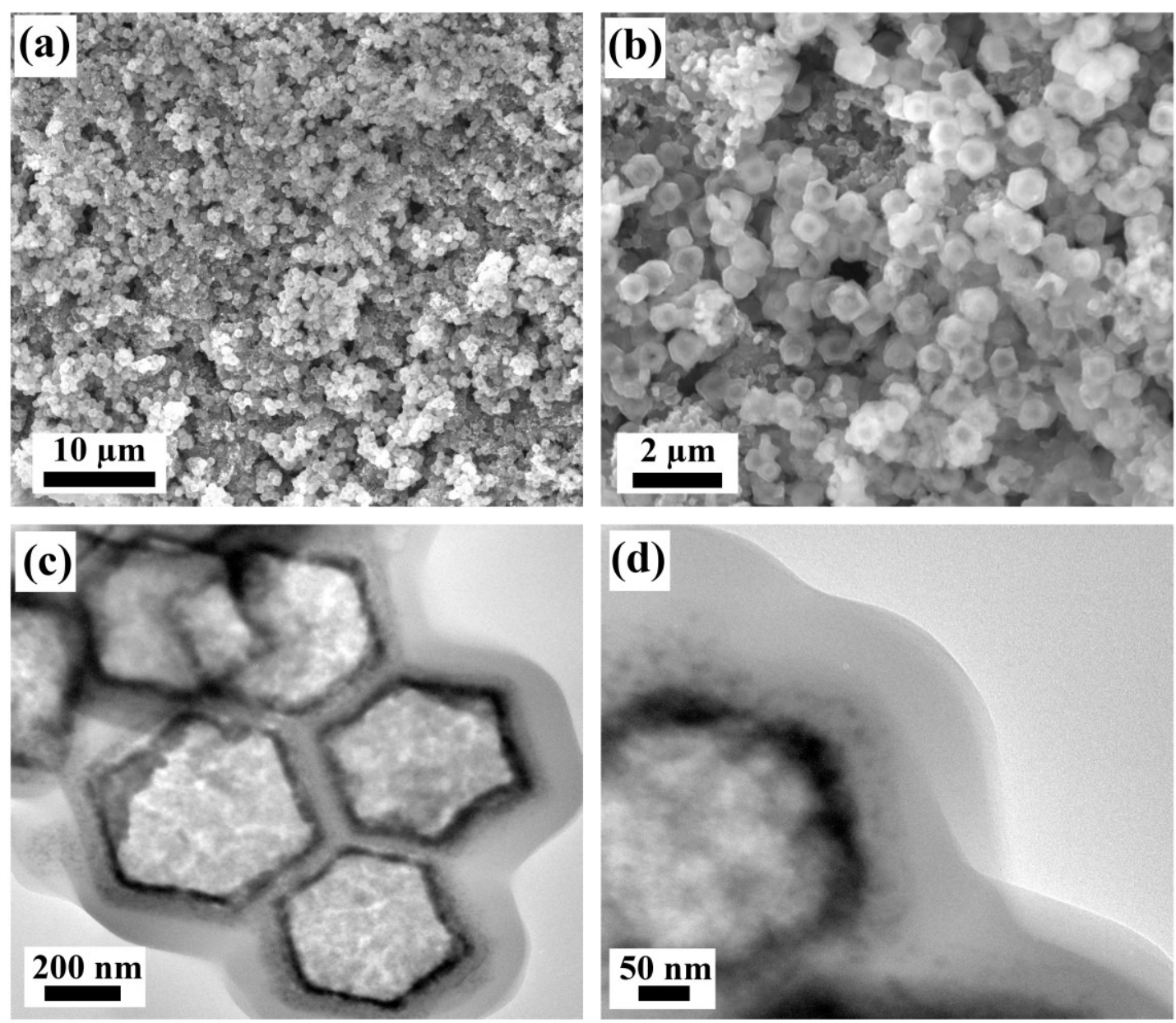

Fig. S20. SEM (a, b) and TEM (c, d) images of $\mathrm{Co}_{9} \mathrm{~S}_{8} / \mathrm{HNCS}$ composite based lithium-ion storage material after 50 charge-discharge cycles at $100 \mathrm{~mA} \mathrm{~g}^{-1}$. 

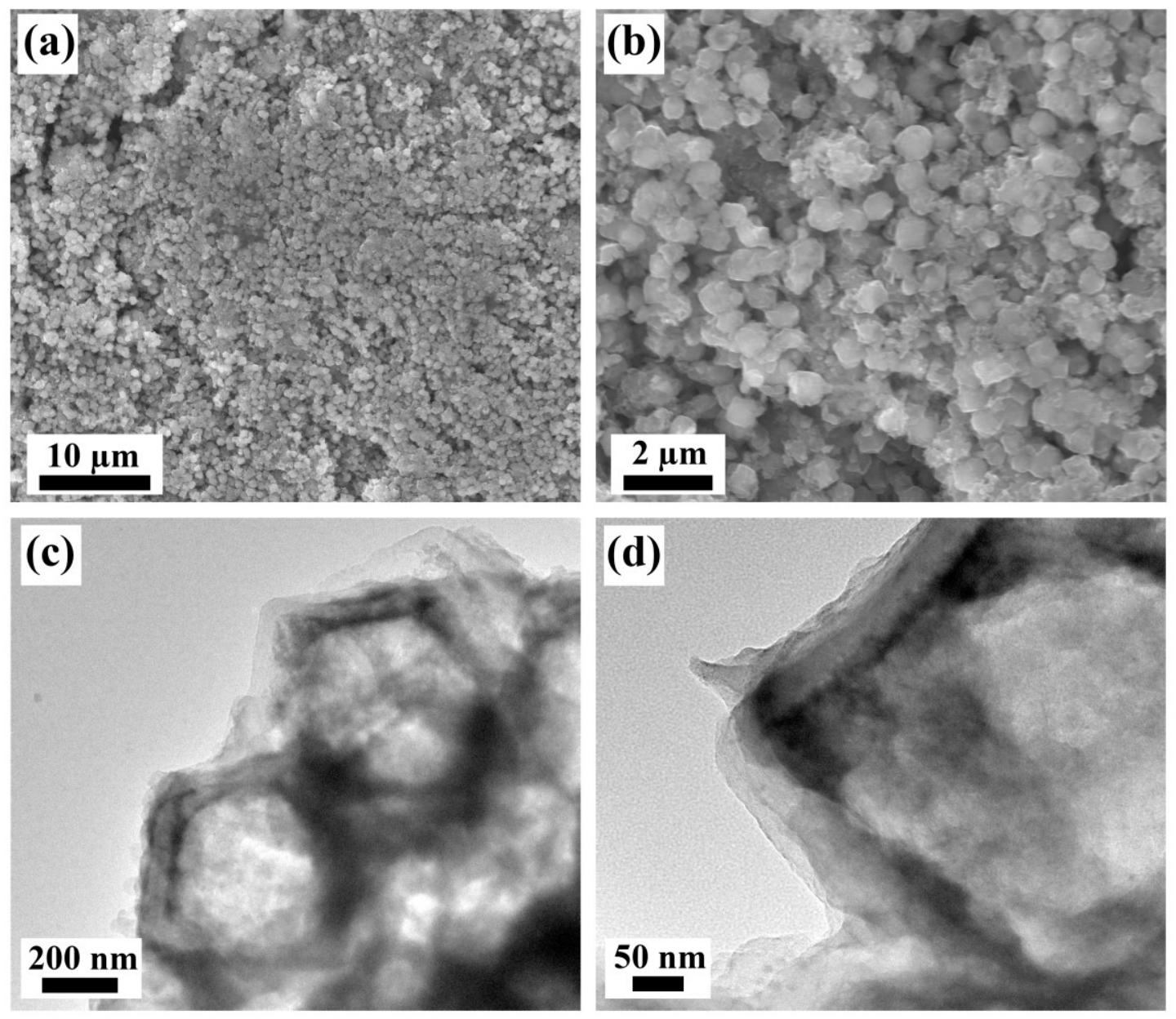

Fig. S21. SEM (a, b) and TEM (c, d) images of $\mathrm{CO}_{9} \mathrm{~S}_{8} / \mathrm{HNCS}$ composite based sodium-ion storage material after 50 charge-discharge cycles at $100 \mathrm{~mA} \mathrm{~g}^{-1}$. 


\section{Supporting references}

[1] R. Jin, J. Zhou, Y. Guan, H. Liu, G. Chen, Mesocrystal $\mathrm{Co}_{9} \mathrm{~S}_{8}$ hollow sphere anodes for high performance lithium ion batteries. J. Mater. Chem. A 2 (2014) 13241-13244.

(2) L. Yu, J. F. Yang, X. W. D. Lou, Formation of $\operatorname{CoS}_{2}$ nanobubble hollow prisms for highly reversible lithium storage. Angew. Chem. Int. Ed. 55 (2016) 13422-13426.

[3] H. Geng, J. Yang, Z. Dai, Y. Zhang, Y. Zheng, H. Yu, H. Wang, Z. Luo, Y. Guo, Y. Zhang, H. Fan, X. Wu, J. Zheng, Y. Yang, Q. Yan, H. Gu, $\mathrm{Co}_{9} \mathrm{~S}_{8} / \mathrm{MoS}_{2}$ yolk-shell spheres for advanced Li/Na storage. Small 13 (2017) 1603490.

[4] J. Lin, J. Cui, F. Cheng, Y. Cui, H. Sun, J. Sun, Self-assembled porous microsized composite of nano- $\mathrm{CO}_{1-\mathrm{x}} \mathrm{S} /$ biomass derived activated carbon by a facile solvothermal method as anode material of lithium ion battery. J. Alloys Compd. 695 (2017) 2173-2179.

[5] W. Shi, J. Zhu, X. Rui, X. Cao, C. Chen, H. Zhang, H. H. Hng, Q. Yan, Controlled synthesis of carbon-coated cobalt sulfide nanostructures in oil phase with enhanced Li storage performances. ACS Appl. Mater. Interfaces 4 (2012) 2999-3006.

[6] M. Wang, J. Zhou, S. Cheng, Q. Pan, M. Yao, Y. Zhu, P. Wu, H. Luo, L. Yang, M. Liu, Template synthesis of carbon-coated $\mathrm{Co}_{9} \mathrm{~S}_{8}$ composite with largely improved capacity for lithium ion batteries. Mater. Lett. 217 (2018) 163-166.

[7] G. Qu, H. Geng, D. Ge, M. Tang, J. Zheng, H. Gu, Porous carbon-wrapped mesoporous $\mathrm{Co}_{9} \mathrm{~S}_{8}$ fibers as stable anode for Li-ion batteries. Electrochim. Acta 211 (2016) 305-312.

[8] R. Tian, Y. Zhou, H. Duan, Y. Guo, H. Li, K. Chen, D. Xue, H. Liu, MOF-derived hollow $\mathrm{Co}_{3} \mathrm{~S}_{4}$ quasi-polyhedron/MWCNT nanocomposites as electrodes for advanced lithium ion batteries and supercapacitors. ACS Appl. Energy Mater. 1 (2018) 402-410.

[9] S. Liu, J. Wang, J. Wang, F. Zhang, L. Wang, Highly uniform $\mathrm{Co}_{9} \mathrm{~S}_{8}$ nanoparticles grown on graphene nanosheets as advanced anode materials for improved Li-storage performance. Appl. Surf. Sci. 390 (2016) 86-91.

[10] H. Wang, S. Lu, Y. Chen, L. Han, J. Zhou, X. Wu, W. Qin, Graphene/Cog ${ }_{8}$ nanocomposite paper as a binder-free and free-standing anode for lithium-ion batteries. J. Mater. Chem. A 3 (2015) 23677-23683.

[11] M. Lu, C. Liao, C. Jiang, Y. Du, Z. Zhang, S. Wu, Remarkable high-temperature performance of hollow $\mathrm{Co}_{9} \mathrm{~S}_{8}$ nanoparticles integrated with carbon materials for lithium-ion batteries. Electrochim. Acta 250 (2017) 196-202.

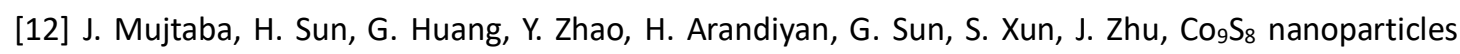
encapsulated in nitrogen-doped mesoporous carbon networks with improved lithium storage properties. RSC Adv. 6 (2016) 31775-31781.

[13] J. Liu, C. Wu, D. Xiao, P. Kopold, L. Gu, P. A. van Aken, J. Maier, Y. Yu, MOF-derived hollow $\mathrm{Co}_{9} \mathrm{~S}_{8}$ nanoparticles embedded in graphitic carbon nanocages with superior Li-ion storage. Small 12 (2016) 2354-2364.

[14] C. Dong, L. Guo, Y. He, L. Shang, Y. Q. Qian, L. Xu, Ultrafine $\mathrm{CO}_{1-x} \mathrm{~S}$ nanoparticles embedded in a nitrogen-doped porous carbon hollow nanosphere composite as an anode for superb sodium-ion batteries and lithium-ion batteries. Nanoscale 10 (2018) 2804-2811.

[15] Q. Zhou, L. Liu, G. Guo, Z. Yan, J. Tan, Z. Huang, X. Chen, X. Wang, Sandwich-like cobalt 
sulfide-graphene composite-an anode material with excellent electrochemical performance for sodium ion batteries. RSC Adv. 5 (2015) 71644-71651.

[16] Z. Shadike, M.-H. Cao, F. Ding, L. Sang, Z.-W. Fu, Improved electrochemical performance of $\mathrm{CoS}_{2}$-MWCNT nanocomposites for sodium-ion batteries. Chem. Commun. 51 (2015) 10486-10489.

[17] Q. Zhou, L. Liu, Z. Huang, L. Yi, X. Wang, G. Cao, $\mathrm{Co}_{3} \mathrm{~S}_{4} @$ Polyaniline nanotubes as high-performance anode materials for sodium ion batteries. J. Mater. Chem. A 4 (2016) 5505-5516.

[18] Z. Zhang, Y. Gan, Y. Lai, X. Shi, W. Chen, J. Li, Cobalt sulfides/dodecahedral porous carbon as anode materials for Na-ion batteries. RSC Adv. 5 (2015) 103410-103413.

[19] Y. N. Ko, Y. C. Kang, $\mathrm{Co}_{9} \mathrm{~S}_{8}$-carbon composite as anode materials with improved Na-storage performance. Carbon 94 (2015) 85-90.

[20] X. Liu, H. Liu, Y. Zhao, Y. Dong, Q. Fan, Q. Kuang, Synthesis of the carbon-coated nanoparticle $\mathrm{Co}_{9} \mathrm{~S}_{8}$ and its electrochemical performance as an anode material for sodium-ion batteries. Langmuir 32 (2016) 12593-12602.

[21] Y. Zhang, N. Wang, P. Xue, Y. Liu, B. Tang, Z. Bai, S. Dou, Cog9 $\mathrm{S}_{8} @$ carbon nanospheres as high-performance anodes for sodium ion battery. Chem. Eng. J. 343 (2018) 512-519.

[22] X. Zhang, H. Wang, G. Wang, Cobalt sulfide nanoparticles anchored in three-dimensional carbon nanosheet networks for lithium and sodium ion batteries with enhanced electrochemical performance.

J. Colloid Interface Sci. 492 (2017) 41-50. 